medRxiv preprint doi: https://doi.org/10.1101/2021.03.26.21254401; this version posted April 23, 2021. The copyright holder for this preprint (which was not certified by peer review) is the author/funder, who has granted medRxiv a license to display the preprint in perpetuity. It is made available under a CC-BY-NC-ND 4.0 International license .

\title{
Subpopulation-specific Machine Learning Prognosis for Underrepresented Patients with Double Prioritized Bias Correction
}

\author{
Sharmin Afrose*, Wenjia Song ${ }^{*}$, Charles B. Nemeroff, Chang Lu, Danfeng (Daphne) Yao \\ Department of Computer Science, Virginia Tech, Blacksburg, VA, USA (S Afrose BS, W Song BS, D \\ Yao PhD); Department of Psychiatry and Behavioral Sciences, the University of Texas at Austin Dell \\ Medical School, Austin, TX, USA (CB Nemeroff MD PhD); Department of Chemical Engineering, \\ Virginia Tech, Blacksburg, VA, USA (C Lu PhD) \\ ${ }^{*}$ Contributed equally \\ \#Corresponding Author: Danfeng (Daphne) Yao, Department of Computer Science, Virginia Tech, \\ Blacksburg, VA 24060, USA. danfeng@vt.edu; +1 (540) 553-5964
}

\begin{abstract}
Clinical datasets are intrinsically imbalanced, dominated by overwhelming majority groups. Off-the-shelf machine learning models optimize the prognosis of majority patient types (e.g., healthy class), causing substantial errors on the minority prediction class (e.g., disease class) and minority subpopulations (e.g., Black or young patients). For example, missed death prediction is 36.6 times higher than non-death cases in a mortality benchmark. Our study also shows that racial and age disparity exists in prediction accuracy. These accuracy disparities have not been systematically reported and common whole-population metrics such as AUC-ROC fail to reflect these serious deficiencies. To correct these biases and improve prediction accuracy for underrepresented subpopulations, we design a double prioritized (DP) technique. Our method trains customized models for specific race or age groups, a substantial departure from the one-model-predicts-all paradigm. We report our findings on four prognosis tasks over two clinical datasets. Our cross-race-group and cross-age-group experiments confirm the need for training specialized prediction models for subpopulations. DP also gives 1.2-58.8 times more balanced recalls and precisions than existing sampling solutions. As underrepresented groups in clinical medicine are a daily occurrence, our contributions likely have broad implications.
\end{abstract}

\section{Introduction}

Researchers have trained machine learning models to predict many diseases and conditions, including Alzheimer's disease ${ }^{1}$, heart disease ${ }^{2}$, risk of developing diabetic retinopathy ${ }^{3}$, cancer risk ${ }^{4}$ and survivability ${ }^{5}$, genetic testing for diseases ${ }^{6}$, hypertrophic cardiomyopathy diagnosis ${ }^{7}$, psychosis $^{8}, \mathrm{PTSD}^{33}$, and COVID-19 ${ }^{9}$. Neural network powered automatic image analysis has also been shown useful for fast disease detection, e.g., breast cancer ${ }^{16}$, and lung cancer ${ }^{38}$. A study showed that deep learning algorithms diagnose breast cancer more accurately $(\mathrm{AUC}=0.994)$ than 11 pathologists ${ }^{16}$. Hospitals (e.g., Cleveland Clinic's partnership with Microsoft ${ }^{10}$, John Hopkins hospital partnership with GE) $)^{11}$ are reported to use predictive analytics for monitoring patients' health status and preventing emergencies ${ }^{12-15}$.

NOTE: This preprint reports new research that has not been certified by peer review and should not be used to guide clinical practice. 1 
However, clinical datasets are intrinsically imbalanced due to the naturally occurring frequencies of data ${ }^{17}$. The data is not evenly distributed across prediction classes (e.g., disease class vs. healthy class), race, age, or other subgroups. One example is pregnant women, who are either excluded from all clinical trials or comprise too small of a sample size to be meaningful. Data imbalance is a major cause of biased prediction results ${ }^{17}$.

Biased prediction results may have serious consequences for some patients. For example, a recent study showed that automatic enrollment of high-risk patients into the health program favors white patients, although black patients had $26.3 \%$ more chronic health conditions than equally ranked white patients $^{18}$. Similarly, algorithmic osteoarthritis pain prediction shows $43 \%$ racial disparities ${ }^{19}$. The design of widely used case-control studies is shown to have temporal bias reducing predictive accuracy ${ }^{40}$. For non-medical applications, researchers also identified serious biases in high-profile machine learning applications, e.g., a widely deployed recidivism prediction tool ${ }^{20-22}$, online advertisement system ${ }^{23}$, Amazon's recruiting engine ${ }^{24}$, and face recognition system ${ }^{25}$. The lack of external validation and overclaiming causal effect in machine learning also raise concerns ${ }^{26}$.

A widely used bias-correction approach to the data imbalance problem is sampling. Oversampling, e.g., replicated oversampling (ROS), is to balance dataset by adding samples of the minority class; undersampling, e.g., random under-sampling (RUS), is to balance dataset by removing samples of the majority class ${ }^{27}$. An improvement is $\mathrm{K}$-nearest neighbor $(\mathrm{K}-\mathrm{NN})$ classifier-based undersampling technique ${ }^{28}$ (e.g., Nearmiss1, Nearmiss2, NearMiss3, Distant) that select samples from majority class based on distance from minority class samples. State-of-the-art solutions are all oversampling methods, including Synthetic Minority Over-sampling Technique (SMOTE) ${ }^{29}$, Adaptive Synthetic Sampling (ADASYN) ${ }^{30}$, and Gamma ${ }^{31}$. All three methods generate new minority points based on existing minority samples, namely using linear interpolation ${ }^{29}$, gamma distribution ${ }^{31}$, or at the class border $^{30}$.

However, existing sampling techniques do not differentiate minority demographic groups (e.g., Black patients or young patients under 30). Thus, it is unclear how well these methods improve predictions on underrepresented patients. In addition, although existing bias correction improves the recall of a minority prediction class (e.g., death), the precision is drastically reduced, e.g., $27.7 \%$ to $78.1 \%$ decrease in our test across four minority demographic subgroups. In other words, with sampling machine learning models predict more minority class cases, however, false positives substantially increase.

Unfortunately, poor prediction performance in minority samples is not reflected in widely used metrics. For imbalanced datasets, conventional metrics such as overall accuracy and AUC-ROC is largely influenced by the performance of majority samples, which machine learning models aim to fit. We examine clinical prediction benchmark ${ }^{14}$ on MIMIC III and cancer survival prediction ${ }^{5}$ on SEER cancer dataset. Both training datasets are imbalanced, in terms of the gender, race, or age distribution. For example, for the in-hospital mortality (IHM) prediction with MIMIC III, 70.6\% data represents White patients, whereas only 9.6\% represents Black patients. MIMIC III and SEER also have data imbalance problems among the two class labels (e.g., death vs. survival). For the IHM prediction, $86.5 \%$ data belongs to patients who did not die in ICU, whereas only $13.5 \%$ of data belongs to the patient who died in hospital. These data imbalances result in serious prediction biases. A typical neural network based machine learning model ${ }^{14}$ that we tested correctly predicts $98.1 \%$ of non-death cases, but only $30.5 \%$ of death cases. Meanwhile, overall accuracy (computed over all patients) is 0.90 and AUC-ROC is 0.86 , as a result of the overwhelmingly good performance in the majority class. These high overall scores are seriously misleading. 
Our study also reveals that accuracy disparity among age or race subgroups can be severe. For example, the mortality prediction precision (i.e., the fraction of actual deaths among predicted deaths) of young patients under 30 is 0.25 , substantially lower than the whole population $(0.68)$. The machine learning model gives better prediction for White (0.70) patients than Black (0.46) and Asian (0.50) patients, for mortality prediction precision. It is important to recognize these accuracy disparities, which helps design AI-based technology to better serve underrepresented patient groups.

Besides identifying various categories of imbalance-induced prediction deficiencies, we present a new technique, double prioritized (DP) bias correction, that improves the prediction accuracy of specific minority demographic groups. A unique feature of DP is its ability to train customized prediction models for specific subpopulations, a drastic improvement over the existing one-model-predicts-all-demographics paradigm. DP differs from state-of-the-art methods, as it strategically prioritizes specific underrepresented groups, as opposed to sampling across the entire patient population. We use DP to optimize the 6 underrepresented demographic subgroups separately, which generates 6 different machine learning models for a prediction task.

We further investigate DP-based machine learning models' specificity in cross-group experiments, where the DP model trained for group A (e.g., Black) is used to predict group B (e.g., Hispanic). Both our cross-race and cross-age-group results strongly suggest racial and age specificities, confirming the need for training specialized machine learning models for underrepresented groups. In the meantime, our results show that model specialization still needs to first build on the whole group samples, which serve as a necessary starting point for training.

In addition, DP uses metrics to incrementally identify the optimal amount of sample enrichment. When applied to neural-network-based machine learning procedures, DP consistently improves minority class recalls while balancing precisions. To quantify this balance, we define a new metric dual-class divergence, which captures the tradeoff between precision and recall - smaller divergence values indicating more balanced precision and recall. DP's dual-class divergence is $1.2-58.8$ times lower than the state-of-the-art sampling methods in the mortality prediction task. Coupled with comparable recall values, these results suggest that DP is more effective at correcting data imbalance for clinical machine learning.

Our findings have broad implications in clinical practice, as underrepresented groups in clinical medicine are a daily occurrence. Our results highlighting racial data imbalance and model specificity also have implications in genetics, because of differences in the frequency of common genetic variants in ethnic groups.

\section{Methods}

Double prioritized (DP) bias correction method. DP prioritizes a specific demographic subgroup (e.g., Black patients) that suffers from data imbalance by replicating minority prediction class (C1) cases from this group (e.g., Black in-hospital deaths). DP incrementally increases the number of duplicated units and chooses the optimal unit number based on resulting models' performance. Figure 1 shows the machine learning workflow with DP bias correction. The main steps are described next. 
Bias testing examines the ratio among different demographic subgroups (e.g., gender, ethnicity, age) and ratio among different prediction classes (e.g., death vs. survival), as well as any disparity in prediction accuracy. If a group has a relatively low number of cases, enrichment is required.

Sample enrichment replicates minority class C1 samples in the training dataset for a target demographic group $g$ up to $n$ times. Each time, duplicated samples are merged with the original training dataset, which forms a new training dataset. Thus, we obtain $n+1$ sets of training datasets, including the original one. Our experiment sets $n$ to 19. The value $n$ can be empirically determined based on prediction performance.

Candidate training is to generate a set of candidate machine learning models. Each of the $n+1$ datasets is used to train and generate a candidate machine learning model. Two types of neural networks are used, long short-term memory (LSTM) model and multilayer perceptron (MLP) model. Following Harutyunyan et al, ${ }^{14}$ for the hospital record prediction tasks, patients' data is preprocessed into time-series records and fed into a LSTM model. Cancer survivability prediction utilizes a MLP model, following Hegselmann et $a l .{ }^{5}$ Prediction and data analysis code is in Python programming language. The hospital record prediction tasks were executed on a virtual machine with Ubuntu 18.04 operating system, x86-64 architecture, 8 cores, 40 GB RAM, and 1 GPU. Cancer survivability prediction tasks were performed using a virtual machine with Ubuntu 18.04 operating system, x86-64 architecture, 22 cores, 32 GB RAM, and 1 GPU. Model parameters remain constant in different bias correction techniques (supplementary table 1).

Model selection is to identify the optimal machine learning model among the $n+1$ candidate models. We choose a final machine learning model $M^{*}$ after evaluating all candidate models' performance as follows. For each model, we then compute two metrics on the test dataset, balanced accuracy (i.e., average recall of both $\mathrm{C} 0$ and $\mathrm{C} 1$ classes, supplementary equation 6) and the area under curve (AUC) of minority class C1's precision-recall curve (denoted by AUC-PR_C1 or PR_C1). We identify the top three models with the highest balanced accuracy values and select the model that gives the highest PR_C1. No enrichment is applied to the test dataset.

Prediction applies model $M^{*}$ to new patients' records of minority group $g$ ' and obtains a binary class label. For deployment, the demographic group $g$ of duplicated samples during Sample enrichment and tested group g' should be consistent, e.g., DP model trained with duplicated Black samples is used to predict new Black patients. Evaluation metrics include accuracy, balanced accuracy, AUC-ROC score, precision, recall, AUC-PR, and F1 score of minority and majority prediction classes, whole population, and various demographic subgroups, including gender (male, female), ethnicity (White, Black, Hispanic, Asian), and 8 age groups. Minority class $\mathrm{C} 1$ precision and $\mathrm{C} 1$ recall are two mostly used metrics in our paper. $\mathrm{C} 1$ precision calculates the fraction of actual minority $\mathrm{C} 1$ class cases among predicted ones. $\mathrm{C} 1$ recall calculates the fraction of $\mathrm{C} 1$ cases that are predicted by a machine learning model. We define a new metric divergence to capture the disparity between precision and recall. Equation 1 shows the dual-class divergence computation for both classes $\mathrm{C} 1$ and $\mathrm{C} 0$. Single-class divergence for $\mathrm{C} 1$ or $\mathrm{C} 0$ can also be computed (supplementary equations 10-11). All other metrics are defined in supplementary equations.

$$
\text { Dual-class divergence }=\frac{\mid \text { Recall C1 }- \text { Precision } C 1|+| \text { Recall C } 0-\text { Precision C } 0 \mid}{2}
$$


medRxiv preprint doi: https://doi.org/10.1101/2021.03.26.21254401; this version posted April 23, 2021. The copyright holder for this preprint (which was not certified by peer review) is the author/funder, who has granted medRxiv a license to display the preprint in perpetuity. It is made available under a CC-BY-NC-ND 4.0 International license .

In addition to regular evaluation, we perform a series of cross-group experiments to assess the specificity of DP-based machine learning models, where duplicated samples and tested samples are from different demographic groups, i.e., $g$ and $g$ ' differ in cross-group evaluation.

Other bias correction techniques compared. The eight existing sampling approaches being compared include four undersampling techniques (namely, random undersampling, NearMiss1, NearMiss3, distant method), and four oversampling techniques (namely, replicated oversampling, SMOTE, ADASYN, Gamma). Undersampling balances the distribution of the two prediction classes by selecting only a subset of the majority class cases. Oversampling balances the dataset by populating the minority class.

Clinical datasets. We use MIMIC III $^{14,32}$ and SEER ${ }^{35}$ cancer datasets, both collected in US. We test existing machine learning models in a clinical prediction benchmark ${ }^{14}$ for MIMIC III and cancer survival prediction $^{5}$ for SEER. We study a total of four binary classification tasks, in-hospital mortality (IHM) prediction and decompensation prediction from the clinical prediction benchmark, ${ }^{14} 5$-year breast cancer survivability (BCS) prediction, and 5-year lung cancer survivability (LCS) prediction. In what follows, we denote the minority prediction class as Class 1 (or $\mathrm{C} 1$ ) and the majority class as Class 0 (or $\mathrm{C} 0$ ).

Figure 2B shows the percentages of different subgroup sizes for training dataset used in BCS prediction. The BCS training set contains 199,000 samples, of which $87.3 \%$ are in Class 0 (i.e., patients diagnosed with breast cancer and survived more than 5 years) and $0.6 \%$ are males. The majority race group (81\%) is White. When categorizing by age, $70 \%$ of the patients are between 40 and 70 . The LCS training dataset (of size 164,443) follows similar imbalanced distributions (supplementary Figure S1B).

Figure 2D shows the composition of IHM training data, which contains 14,681 time-series samples from MIMIC III. The majority of the records $(86.5 \%)$ belong to Class 0 (i.e., patients who do not die in hospital). The rest (13.5\%) belong to Class 1 (i.e., the patients who die in hospital). $70.6 \%$ of the patients are White and $76 \%$ belong to the age range $[50,90)$. The training set contains insufficient data for the young adult population. Distributions of the decompensation training dataset (of size 2,377,768) are similar (Supplementary Figure S1D).

\section{Results}

Accuracy disparity between majority and minority prediction classes without bias correction.

Without any bias correction, the original machine learning model demonstrates substantial accuracy disparity between the majority prediction class $\mathrm{C} 0$ and the minority prediction class $\mathrm{C} 1$. Figure $2 \mathrm{~A}$ shows the 5-year breast cancer survivability (BCS) prediction results for various subpopulations. For the $[30,40)$ age group, the recall, precision, and AUC-PR for majority class $\mathrm{C} 0$ are all over 0.9 , while for $\mathrm{C} 1$ merely $0.41,0.69$, and 0.57 are observed, respectively. A similar trend is observed for the in-hospital mortality (IHM) prediction with the MIMIC III dataset (Figure 2C). For example, 1.9\% of non-death cases (class $\mathrm{C} 0$ ) in IHM prediction are wrong, whereas the missed mortality prediction (class $\mathrm{C} 1$ ) is $69.5 \%, 36.6$ times. For Black patients, while recall, precision, and AUC-PR are all above 0.9 for $\mathrm{C} 0, \mathrm{C} 1$ recall is 0.18 , which means that for every 100 Black patients who die in hospital, the model would mispredict 82 of them. 
The overall accuracy and AUC-ROC combine the results of both majority $\mathrm{C} 0$ and minority $\mathrm{C} 1$ classes. These values are consistently high ( $>0.85$ in most cases) across all tasks and subgroups, even when $\mathrm{C} 1$ recalls are dismal (Figure 2). These values are dominated by the overwhelmingly high precision and recall ( $>0.9$ in most cases) of the majority prediction class $\mathrm{C} 0$. Thus, these commonly used metrics in prediction do not reflect the minority class performance under data imbalance.

Accuracy disparity across demographic subgroups without bias correction. Besides disparity between prediction classes, the original model also shows disparity across demographic subgroups. For the BCS task (Figure 2A), the disparity among age subgroups is severe. The minority class $\mathrm{C} 1$ recall of age group $<30(0.29)$ is only $39 \%$ of that of the $90+$ age group $(0.75)$, resulting in a large 0.46 gap. This young patients group's $\mathrm{C} 1$ recall $(0.29)$ is also significantly lower than the whole population's $(0.50) .<30$ group also has the lowest $\mathrm{C} 1$ precision, 0.20 lower than $[80,90)$ population. Racial disparity also exists, but appears less pronounced. The largest $\mathrm{C} 1$ recall difference is 0.13 between Asian (0.44) and Black $(0.57)$ and $\mathrm{C} 1$ precisions are all in the range of $[0.68,0.75]$.

For the IHM prediction (Figure 2C), Black patients have the lowest minority class $\mathrm{C} 1$ recall (0.18), lower than the whole group (0.31) and Hispanic patients (0.5). Black also has the lowest $\mathrm{C} 1$ precision (0.46), similar to Asian (0.50), both much lower than White (0.70). The disparity among C1 recalls of various age subgroups is low, all in the range of [0.23, 0.39]. Most subgroups have somewhat similar $\mathrm{C} 1$ precision values, except the $<30$ group. Young patients under 30 have a low $\mathrm{C} 1$ precision of 0.25 , substantially lower than the whole population $(0.68)$.

Both gender groups perform similarly in both tasks, despite the fact that male patients only account for $0.6 \%$ of the samples in the SEER dataset for BCS prediction (Figures $2 \mathrm{~B}$ ). Young patients under 30 age group account for only $0.6 \%$ and $4 \%$ in SEER (Figures $2 \mathrm{~B}$ ) and MIMIC III datasets (Figure $2 \mathrm{D})$, respectively. Their predictions are consistently poor. Despite the large disparity in minority class $\mathrm{C} 1$ performance, majority class $\mathrm{C} 0$ precisions and recalls are consistently high for all subgroups, with most values above 0.90 . Despite small sample sizes, some minority demographic groups (e.g., $90+$ groups in BCS prediction) have high prediction accuracies even without sampling.

DP-based machine learning models optimized for subpopulations. We use the DP bias correction method to optimize models for the 6 underrepresented demographic subgroups separately, which generates 6 different machine learning models for each prediction task. Each model is specifically trained to predict for the target population. We show the minority class $\mathrm{C} 1$ percentages in the training datasets within subgroups before and after applying DP bias correction in both BCS and IHM predictions (Supplementary Tables 2-3). The number of added minority units corresponding to the optimal DP model varies substantially. It ranges from 2 units for $90+$ age group to 11 units for Asian and $<30$ age group in BCS prediction (Supplementary Table 2). For IHM prediction, the number ranges from 1 additional unit for Asian and Hispanic groups to 11 units for 90+ age group (Supplementary Table 3). Similarly, after enrichment, the percentage of $\mathrm{C} 1$ cases in the training dataset corresponding to the DP model also varies, not necessary around $50 \%$.

Compared to the original model, DP significantly increases the recalls of all groups for BCS prediction and most groups for IHM prediction (Figure 3). C1 recall of several groups doubles or nearly doubles. For example, $\mathrm{C} 1$ recall of $90+$ group jumps from 0.23 to 0.52 in IHM prediction (Supplementary Table 3) and 
medRxiv preprint doi: https://doi.org/10.1101/2021.03.26.21254401; this version posted April 23, 2021. The copyright holder for this preprint (which was not certified by peer review) is the author/funder, who has granted medRxiv a license to display the preprint in perpetuity. It is made available under a CC-BY-NC-ND 4.0 International license .

from 0.29 to 0.52 for $<30$ age group in BCS prediction (Supplementary Table 2). Most groups' C1 precisions are reduced compared to the original model without DP, e.g., from 0.6 to 0.5 for $<30$ age group in BCS prediction (Supplementary Table 2). This reduction is expected due to the general tradeoff between precision and recall. However, there are exceptions. For example, DP substantially increases both the $\mathrm{C} 1$ recall and precision for Black in IHM prediction from 0.18 to 0.32 and from 0.46 to 0.60 , respectively (Supplementary Table 3). We also find three more cases in the lung cancer survivability prediction and decompensation prediction tasks with smaller increases (Supplementary Tables 4 and 5).

For Asian and $<30$ age group in the IHM prediction, DP does not improve the original models' C1 recalls, partly due to missing attributes and different feature representations in the very small number of test samples. For example, the test dataset only has 3 deceased patients in the $<30$ age group and 9 deceased Asian patients.

Race- and age-specificity of DP models. In our cross-group experiments, we use the DP model trained for group A (e.g., Black) to predict group B (e.g., Hispanic). This cross application aims to evaluate the specificity of machine learning models with respect to race and age. We perform both cross-race and cross-age-group experiments for BCS prediction (Figure 4) and IHM prediction (Supplementary Figure $\mathrm{S} 2$ ). In most cases, the minority class $\mathrm{C} 1$ recall and balanced accuracy are the highest when the race or age group of patients being predicted on matches the race or age group that the DP model is designed for.

BCS model's race specificity is obvious. For example, when predicting Asian patients' breast cancer survivability, the DP Asian model (0.769) outperforms the DP Black model (0.439), DP Hispanic model (0.364), and the original model without DP (0.439) in terms of minority class $\mathrm{C} 1$ recall (Figure 4A). A similar-but-less-pronounced trend is observed in the IHM prediction for Hispanic and Black, i.e., DP models specifically trained for them outperform other models when being used to predict Hispanic or Black patients, respectively (Supplementary Figure S2A, B). These observations indicate DP models' specificity with respect to race, also confirming the need for training specialized machine learning models for individual underrepresented ethnic groups.

Model specificity is distinctively observed for the $90+$ age group, as the minority class $\mathrm{C} 1$ recall on $90+$ patients is the highest when its specific DP model is used in the BCS prediction (Figure 4C) and IHM prediction (Supplementary Figure S2C). When making BCS prediction on $90+$ years old patients, DP 90+ model (0.830) outperforms the DP $<30$ model $(0.661)$, DP $[30,40)$ model $(0.714)$, and the original model ( 0.750$)$ in terms of $\mathrm{C} 1$ recall (Figure $4 \mathrm{C}$ ). A more drastic trend is observed in the IHM prediction, when the DP $90+$ model gives 2 to 3 times $\mathrm{C} 1$ recall than the other models (Supplementary Figure S2C).

The model specificity between $[30,40)$ and $<30$ age groups is weak. For example, when predicting BCS on age group $<30$, the DP $[30,40$ ) model outperforms the DP $<30$ model, suggesting possibly merging the two age groups during training in the future (Figure 4C). The overall age specificity in the IHM prediction (Supplementary Figure S2C) is weaker than that of BCS prediction.

Reduction in precision after bias correction. The eight existing sampling methods improve the recall of the minority class $\mathrm{C} 1$, while drastically decreasing the precision of $\mathrm{C} 1$, i.e., introducing more false positives (Figure 5). For example, for Black patients in the BCS prediction, the $\mathrm{C} 1$ recall increment ranges from $28.3 \%$ (NearMiss 3 ) to $72.0 \%$ (NearMiss1) when compared to the original model after 
medRxiv preprint doi: https://doi.org/10.1101/2021.03.26.21254401; this version posted April 23, 2021. The copyright holder for this preprint (which was not certified by peer review) is the author/funder, who has granted medRxiv a license to display the preprint in perpetuity. It is made available under a CC-BY-NC-ND 4.0 International license .

applying existing sampling methods (Figure 5A). Although this tradeoff between precision and recall is expected, the decrease in precision is rather significant for some existing sampling methods, e.g., $65.3 \%$ reduction for NearMiss1. For patients in age $90+$ group in the IHM prediction, C1 recall in sampled models shows $180.2 \%$ (RUS) to $280.6 \%$ (NearMiss 1 ) increase, compared to the original model (Figure 5B). It means that more mortality cases are correctly predicted. In the meantime, existing sampling methods show $27.7 \%$ (SMOTE) to $51.0 \%$ (Distant) decrease in $\mathrm{C} 1$ precision, compared to the original, giving more false positives.

All eight existing sampling methods artificially force the class ratio to be 1:1. Among them, three undersampling methods (namely, NearMiss1, NearMiss3, and distant method) perform worse than the others, in terms of minority class C1 AUC-PR (Figure 5). In all cases, sampling does not substantially impact majority class $\mathrm{C} 0$ performance. AUC-PR C0 scores of all sampled models are comparable to that of the original model. Similar trends are observed for age group [30,40) for BCS prediction and Black patients in IHM prediction (Supplementary Figure S3).

DP increases minority class recall while balancing precision. DP increases the original model's minority class $\mathrm{C} 1$ recall without substantially sacrificing $\mathrm{C} 1$ precision (Figures 5, 6), a substantial improvement over the state-of-the-arts. For example, DP increases $\mathrm{C} 1$ recall by $130.4 \%$ for age $90+$ group in IHM prediction, while showing higher $\mathrm{C} 1$ precisions than all other sampling techniques (Figure 6B). Compared with state-of-the-art solutions (e.g., Gamma, ADASYN, SMOTE), DP method offers a substantially more balanced performance for minority class $\mathrm{C} 1$. We further measure them based on the divergence metric next.

In terms of both dual-class and $\mathrm{Cl}$ divergences, DP produces lower scores than state-of-the-art sampling solutions (e.g., Gamma, ADASYN, SMOTE) (Figure 6 top). Lower divergence indicates more balanced recall and precision. While producing recall values comparable to state-of-the-arts, DP gives balanced minority class $\mathrm{C} 1$ precisions and recalls (Figure 6 bottom). For BCS prediction, existing sampling techniques show 1.33 (SMOTE) to 4.62 (NearMiss1) times higher dual-class divergence than DP for Black (Figure 6A). For IHM prediction, existing samplings show 24.4 (RUS) to 58.8 (NearMiss1) times higher dual-class divergence than DP for 90+ patients (Figure 6B). Similar trends are observed for $[30,40)$ group in BCS prediction (the exception of NearMiss3) and Black patients in IHM prediction (Supplementary Figure S4).

5-year lung cancer survivability (LCS) prediction and decompensation prediction. We repeat the experiments for the other two tasks, 5-year lung cancer survivability (LCS) prediction and decompensation prediction, and observe similar patterns. For LCS prediction on SEER dataset, the minority Class 1 represents patients who survive lung cancer for at least 5 years after the diagnosis. Without any bias correction, the recall, precision, AUC-PR are all above 0.93 for Class 0 , while the values for Class 1 are only $0.60,0.72$, and 0.73 , respectively (Supplementary Figure S1A). Regarding the disparity among demographic subgroups, the original model misses only $15 \%$ of survival cases in the age $[30,40)$ group, while it misses $42 \%$ and $59 \%$ of them in $[70,80)$ and $[80,90)$ age groups, respectively. For decompensation prediction on MIMIC III dataset, the minority class C1 represents patients whose health condition deteriorates after 24 hours. We also observe the accuracy disparity among Class 1 and Class 0 without any bias correction. For example, $\mathrm{C} 1$ recall is merely 0.13 , while $\mathrm{C} 0$ recall is near perfect 
medRxiv preprint doi: https://doi.org/10.1101/2021.03.26.21254401; this version posted April 23, 2021. The copyright holder for this preprint (which was not certified by peer review) is the author/funder, who has granted medRxiv a license to display the preprint in perpetuity.

It is made available under a CC-BY-NC-ND 4.0 International license .

(Supplementary Figure S1C). The disparity also exists among demographic subgroups, e.g., C1 precision is 0.91 for Asians and only 0.35 for Hispanics.

For LCS prediction, sampling results for two minority demographic groups, namely Asian and age group [30, 40) are shown in Supplementary Figure S5. Because of the class distribution in the [30, 40) subgroup is more balanced (33\% Class 1, Supplementary Table 4), the original C1 precision and recall are high ( 0.85 for both). After applying DP bias correction, both values only slightly increase by $2.5 \%$. Results of other sampling methods in LCS prediction follow the similar pattern as the BCS prediction. For decompensation prediction, we apply two most commonly used sampling techniques, random undersampling (RUS) and replicated oversampling (ROS). We have to exclude other sampling techniques as their pairwise quadratic distance computation is expensive for 2,377,768 patients' time series training dataset. Overall, RUS performs the worst in terms of both $\mathrm{C} 1$ recall and precision (Supplementary Figure S6) as RUS discards around 94\% of data (decompensation C1 is 2\%) which contributes to a huge loss of information. ROS shows a higher recall with a low precision rate than DP. When applying ROS sampling on Black patients, C1 recall increases $320.2 \%$, whereas $\mathrm{C} 1$ precision decreases $88.9 \%$ compared to the original model. Supplementary Table 5 shows the number of additional units of specific $\mathrm{C} 1$ subgroup samples in DP for the decompensation prediction.

Consistent with other prediction tasks, DP shows low divergence between precision and recall (Supplementary Figures S7 and S8). In LCS prediction, for Asian patients, existing sampling techniques show 1.07 (SMOTE) to 7.90 (NearMiss1) times dual-class divergence compared to DP's (Supplementary Figures S7A). For age $[30,40)$ patients, DP shows perfectly balanced precision and recall (0 divergence). For decompensation prediction on Black patients, the DP model improves $\mathrm{C} 1$ recalls by $158 \%$ and shows 3.5 times lower divergence score compared to the original model (Supplementary Figure S8A).

We also use DP to train specialized machine learning models that optimize the prediction for each of the 6 underrepresented demographic subgroups for LCS and decompensation predictions. For all subgroups in the LCS and decompensation predictions, DP increases C1 recalls while balancing C1 precisions (Supplementary Figure S9), consistent with earlier observations. These results further confirm the feasibility of training subpopulation-specific prognosis models.

\section{Discussion}

Because underrepresentation is prevalent in clinical medicine, our findings likely have broad implications beyond the specific datasets and minority groups studied. Fully understanding the accuracy gaps associated with imbalanced data helps reduce life-threatening prediction mistakes. A key first step is to identify the minority prediction class and minority demographic groups in the training dataset. Vast disparity exists between minority $\mathrm{C} 1$ and majority $\mathrm{C} 0$ classes and among demographic subgroups. For example, young patients under 40 are underrepresented in SEER and MIMIC III and consistently exhibit low $\mathrm{C} 1$ recalls.

Conventional machine learning prognoses follow a one-model-predicts-all-demographics paradigm. In contrast, the DP technique enables one to train models for specific underrepresented age or 
racial groups, not having to use the same model for the entire patient population. Our age model specificity results strongly suggest training a specific machine learning model for the oldest-old age group (typically defined as $85+)^{36}$, a growing population in the $\mathrm{US}^{37}$. Our experiment also suggests that machine learning prognosis models need to recognize racial heterogeneity, as we find that a model optimized for one race (e.g., White) may not predict well on another race. This trend is consistent in both the SEER and MIMIC III datasets, indicating the existence of unique racial features. Models from adjacent age groups, e.g., $<30$ and [30, 40), exhibit some compatibility. DP's ability to support heterogeneity in machine learning design is also potentially useful for prediction problems where diverse patterns are expected, e.g., distinct posttraumatic stress responses in subpopulations ${ }^{34}$.

Model specialization still needs to rely on the whole group samples. Training a model solely based on particular subgroup samples (e.g., Black patients) gives poor results, worse than the original model on almost all metrics, due to small sample sizes. For example, in IHM prediction for Black patients, the subgroup training approach shows $40.2 \%$ decrease in $\mathrm{C} 1$ recall from the original model (without sampling) and $66.7 \%$ decrease from the DP model. For BCS prediction, $\mathrm{C} 1$ recall and precision of most minority race subgroups are lower than the original model, e.g., $12.9 \%$ decrease for Hispanic $\mathrm{C} 1$ recall and $6.7 \%$ for Black $\mathrm{C} 1$ precision. This result suggests the importance of involving all samples in training, which forms a necessary starting point for further model optimization. The whole population training takes the full advantage of shared evolutionary features before subsequent model specialization.

Our results suggest that prioritized bias correction is highly effective for improving $\mathrm{C} 1$ recalls of minority demographic groups. DP maintains the balance between minority class $\mathrm{C} 1$ recall and precision (i.e., low divergence), while boosting $\mathrm{C} 1$ recall. By enriching specific minority demographic $\mathrm{C} 1$ samples, as opposed to the entire $\mathrm{C} 1$ population (as in all existing sampling methods), DP improves the model's specificity for that subgroup.

Our DP method is designed to gradually and dynamically determine the optimal enrichment ratio based on metrics, providing both flexibility and oversight when designing and executing sample enrichment. In contrast, existing sampling practices artificially force the class ratio to reach 1:1, which results in drastic precision reduction. We observe that after a certain number of units, further increase may lead to plateaued recall but substantially decreased precision of the minority class. This observation shows the importance of dynamically monitoring the minority class performance during bias correction.

When training and testing machine learning models, using multiple metrics (e.g., balanced accuracy, separate metrics for the two prediction classes) is crucial. Commonly used metrics (e.g., AUCROC, accuracy) are heavily influenced by the majority class and fail to reflect any poor performance in the minority class, when used on imbalanced datasets. Our new divergence metric is useful for capturing the tradeoff between recall and precision. We envision that DP bias correction is universally applicable to all medical datasets, given their intrinsic data imbalance characteristic. Future directions include exploring how data underrepresentation impacts the quality of medical image analysis, as well as mutation-based evolutionary computation ${ }^{39}$. 
medRxiv preprint doi: https://doi.org/10.1101/2021.03.26.21254401; this version posted April 23, 2021. The copyright holder for this preprint (which was not certified by peer review) is the author/funder, who has granted medRxiv a license to display the preprint in perpetuity. It is made available under a CC-BY-NC-ND 4.0 International license .

Contributors. DY conceived and designed the study. DY and CL conceived the DP bias correction method. DY designed the model specificity experiments. SA conducted experiments on MIMIC III and analyzed the data. WS conducted experiments on SEER and analyzed the data. SA and WS cross checked the validity of each other's data. SA and WS designed the sampling comparisons. SA, WS, and DY wrote the manuscript. CL and CBN provided strategic guidance. All authors proofread the manuscript and provided feedback.

Declaration of competing interests. CBN declares consulting for the following companies in the last 12 months: ANeuroTech (division of Anima BV), Taisho Pharmaceutical, Inc., Takeda, Signant Health, Sunovion Pharmaceuticals, Inc., Janssen Research \& Development LLC, Magstim, Inc., Navitor Pharmaceuticals, Inc., Intra-Cellular Therapies, Inc., EMA Wellness, Acadia Pharmaceuticals, Axsome, Sage, BioXcel Therapeutics, Silo Pharma, XW Pharma, Neuritek, Engrail Therapeutics, Corcept Therapeutics Pharmaceuticals Company. CBN owns stock in Xhale, Seattle Genetics, Antares, BI Gen Holdings, Inc., Corcept Therapeutics Pharmaceuticals Company, EMA Wellness. CBN serves on the scientific advisory boards of ANeuroTech (division of Anima BV), Brain and Behavior Research Foundation (BBRF), Anxiety and Depression Association of America (ADAA), Skyland Trail, Signant Health, Laureate Institute for Brain Research (LIBR), Inc., Magnolia CNS. CBN is the board of directors of Gratitude America, ADAA, Xhale Smart, Inc. CBN has patents in antipsychotic drug delivery. All other authors do not have competing interests.

Data Sharing. The MIMIC III and SEER data used in this study are not publicly downloadable but can be requested at their original sites. Parties interested in data access should visit the MIMIC III website (https://mimic.physionet.org/gettingstarted/access/) and the SEER website (https://seer.cancer.gov/data/access.html) to submit access requests.

Code Sharing. We have released all our code used on GitHub. The directory contains the preprocessing code for training data generation for DP, as well as result processing regarding model selection and subgroup result extraction steps. https://github.com/ShaAfr/underrepresentation_in_clinical_dataset 
medRxiv preprint doi: https://doi.org/10.1101/2021.03.26.21254401; this version posted April 23, 2021. The copyright holder for this preprint (which was not certified by peer review) is the author/funder, who has granted medRxiv a license to display the preprint in perpetuity.

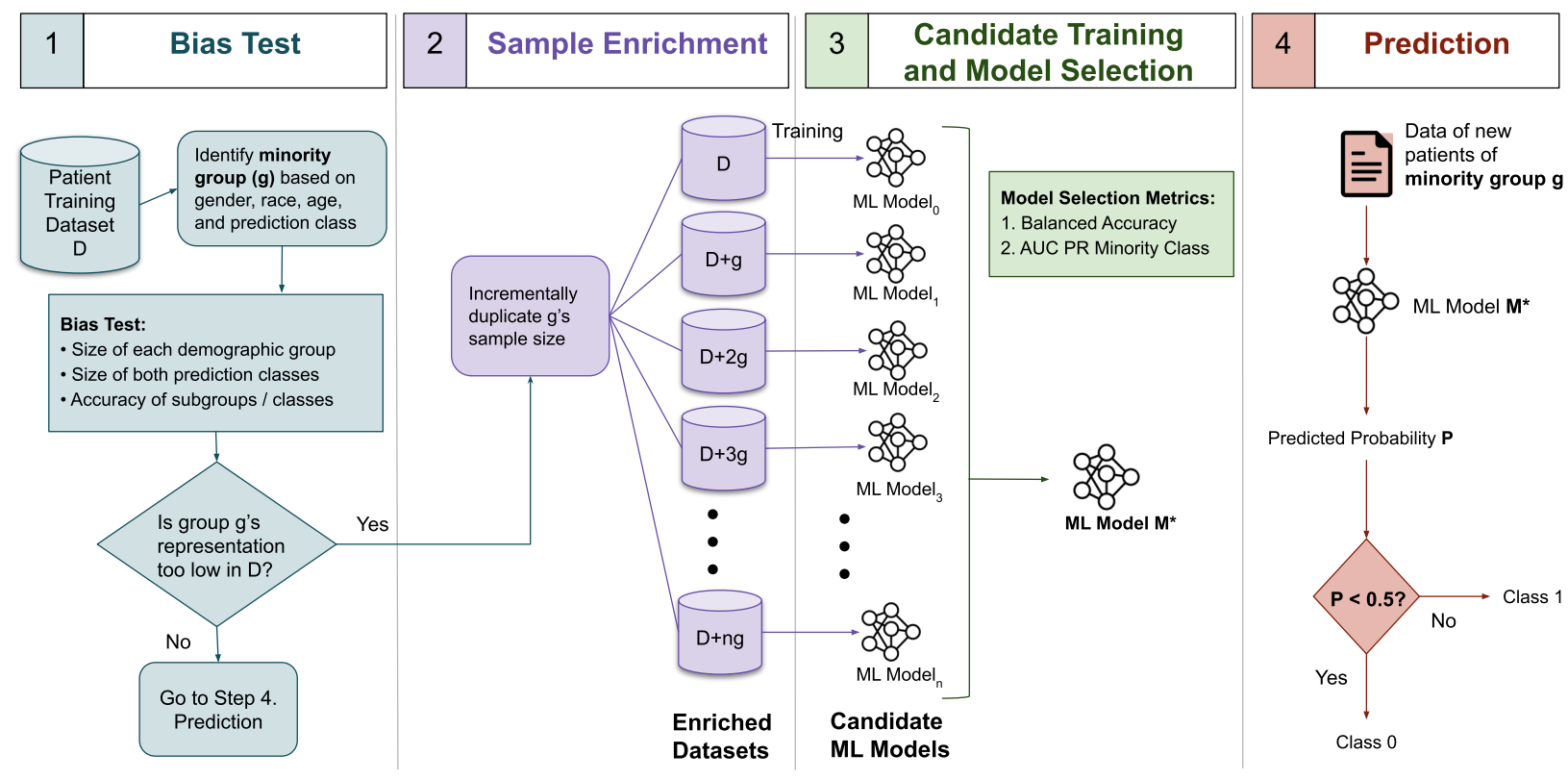

Figure 1: Workflow for improving data balance in machine learning prognosis prediction using double prioritized (DP) bias correction.

Bias testing assesses the distributions of demographic groups and prediction classes in training data; sample enrichment prepares a number of new training datasets by incrementally enriching a specific minority group; candidate training is where each of the $n+1$ datasets is used for training a candidate machine learning model; model selection identifies the optimal model based on balanced accuracy and minority class AUC-PR metrics; prediction applies the selected model on new patient data. AUC-PR represents the area under curve of the precision-recall curve. 
medRxiv preprint doi: https://doi.org/10.1101/2021.03.26.21254401; this version posted April 23, 2021. The copyright holder for this preprint (which was not certified by peer review) is the author/funder, who has granted medRxiv a license to display the preprint in perpetuity.

It is made available under a CC-BY-NC-ND 4.0 International license .

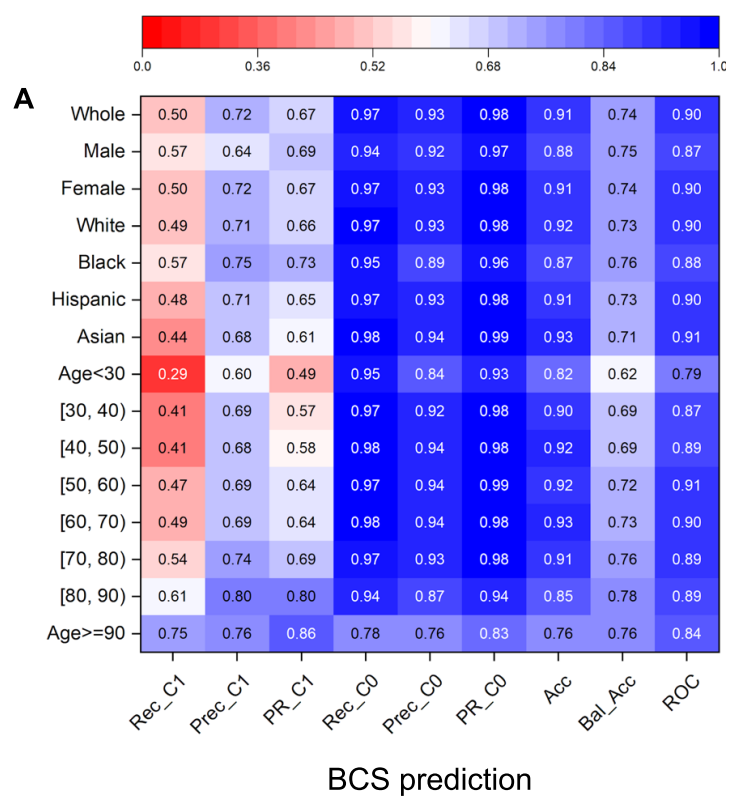

C

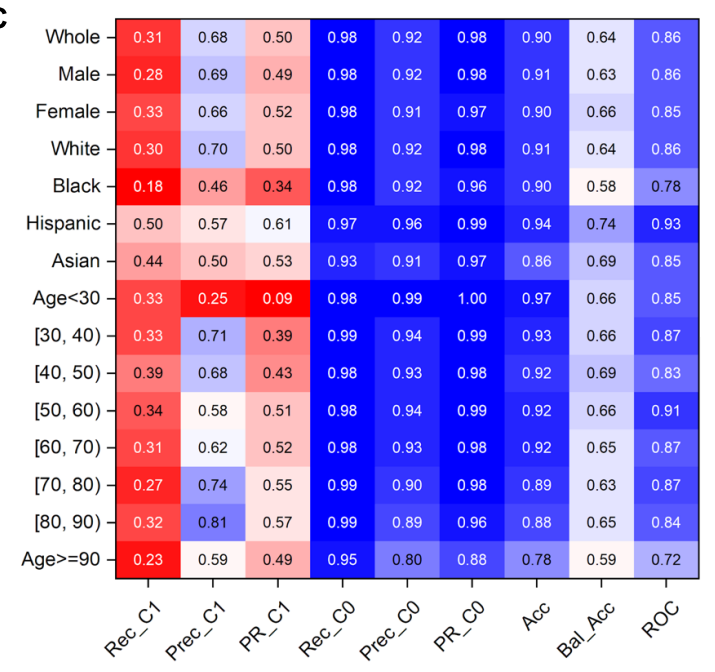

IHM prediction
B
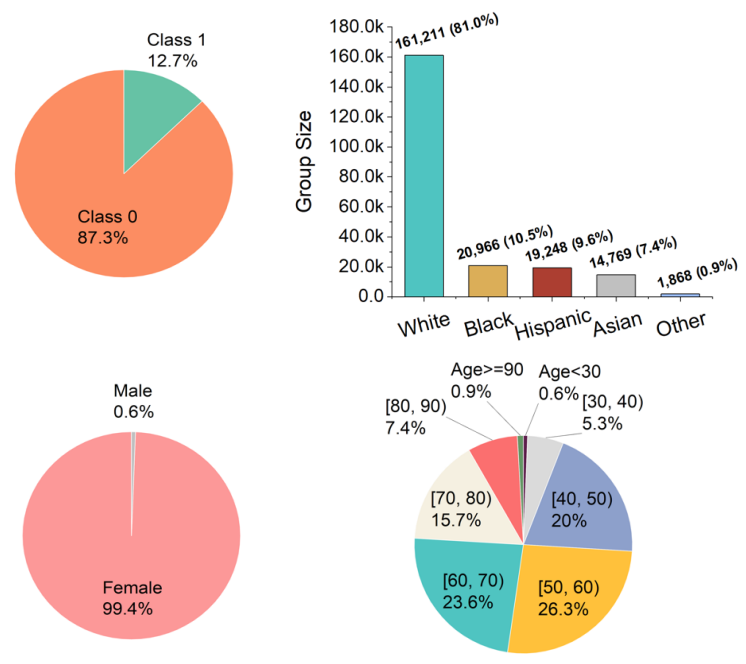

SEER dataset statistics for BCS

D
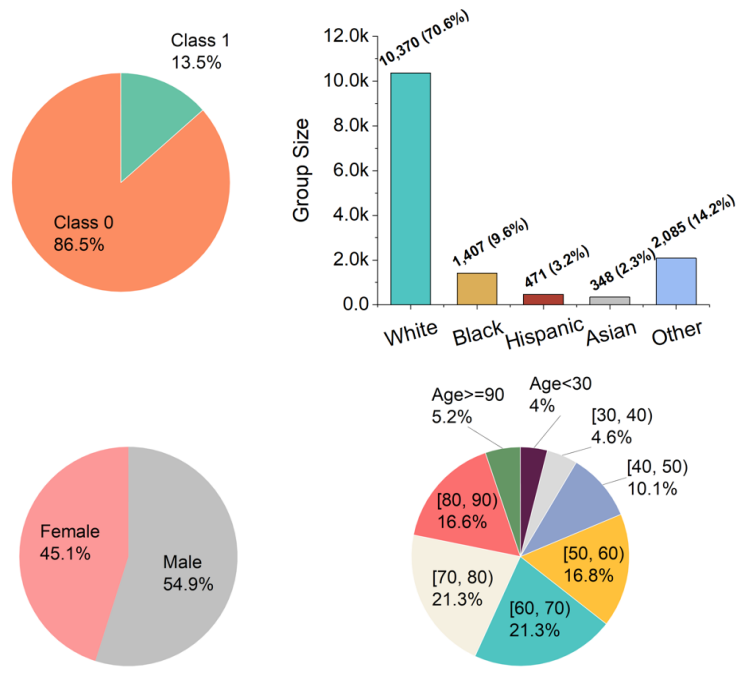

MIMIC dataset statistics for IHM

Figure 2: Prediction results under the original machine learning models (no bias correction) and training data statistics for the 5-year breast cancer survivability (BCS) in (A) and the in-hospital mortality (IHM) tasks in (B). Rec_C1, Prec_C1, PR_C1, Rec_C0, Prec_C0, PR_C0, Acc, Bal_Acc, ROC stand for Recall Class 1, Precision Class 1, Area Under the Precision-Recall Curve Class 1, Recall Class 0, Precision Class 0, Area Under the Precision-Recall Curve Class 0, Accuracy, Balanced Accuracy, Area under the ROC Curve, respectively. (A) Prediction class, racial, gender, age group distribution, and prediction results for the BCS prediction. Class 1, representing death 5 years after breast cancer diagnosis, is the minority prediction class. Class 0 , representing survival after 5 years, is the majority prediction class. (B) Statistics of SEER BCS dataset. (C) Prediction class, racial, gender, age group distribution, and prediction results for the IHM prediction. Class 1, representing death after staying 48 hours in intensive care units at the hospital, is the minority prediction class. Class 0 , representing 
medRxiv preprint doi: https://doi.org/10.1101/2021.03.26.21254401; this version posted April 23, 2021. The copyright holder for this preprint (which was not certified by peer review) is the author/funder, who has granted medRxiv a license to display the preprint in perpetuity.

It is made available under a CC-BY-NC-ND 4.0 International license .

survival after staying 48 hours in intensive care units, is the majority prediction class. (D) Statistics of MIMIC III IHM dataset.

A

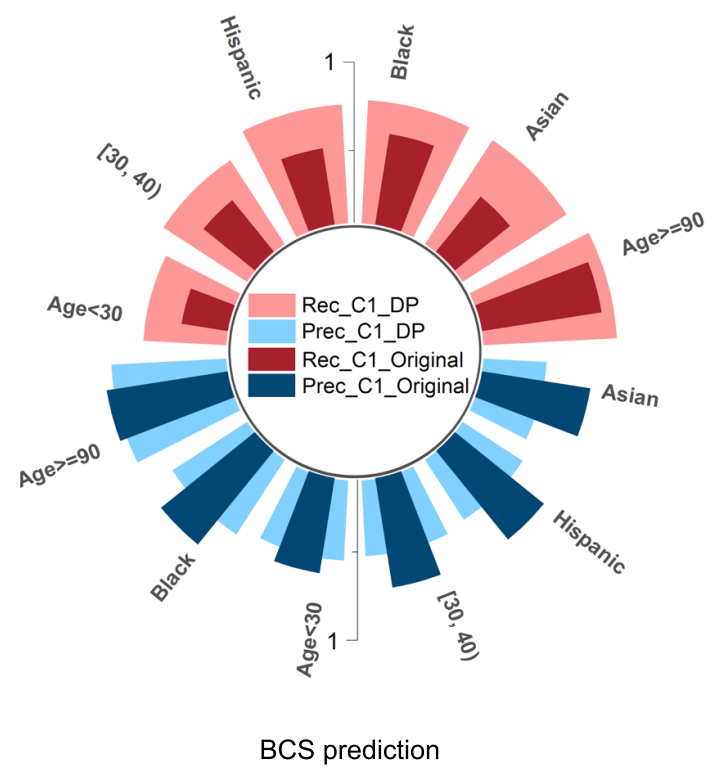

B

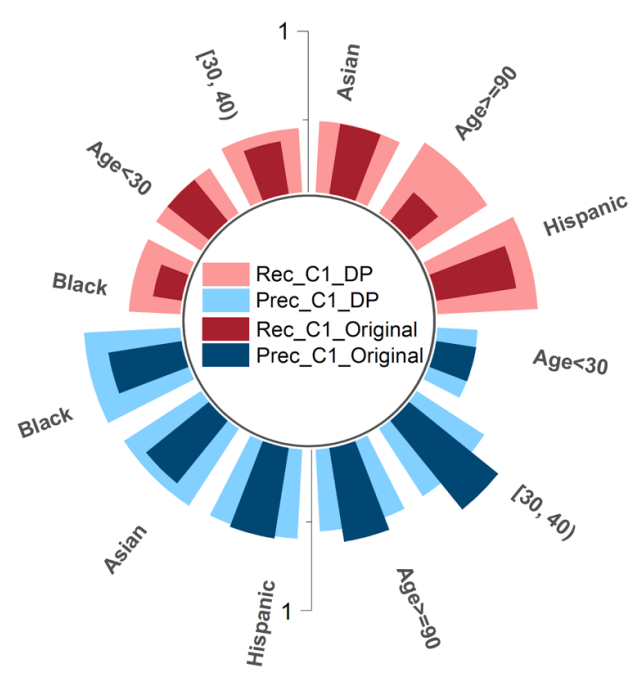

IHM prediction

Figure 3: Minority class $\mathrm{C} 1$ performance, in terms of precision and recall, of six underrepresented demographic subgroups with DP bias correction compared to the original machine learning model without any bias correction in two tasks. (A) The 5-year breast cancer survivability (BCS) prediction with the SEER dataset. (B) The in-hospital mortality (IHM) prediction with the MIMIC III dataset. 
medRxiv preprint doi: https://doi.org/10.1101/2021.03.26.21254401; this version posted April 23, 2021. The copyright holder for this preprint (which was not certified by peer review) is the author/funder, who has granted medRxiv a license to display the preprint in perpetuity.

It is made available under a CC-BY-NC-ND 4.0 International license .

A

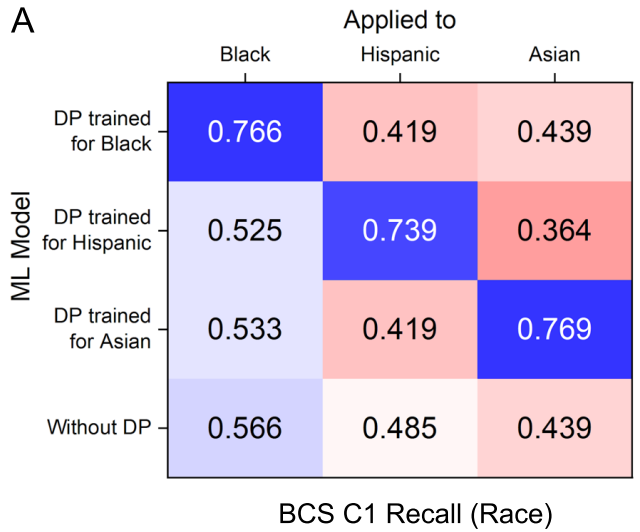

C

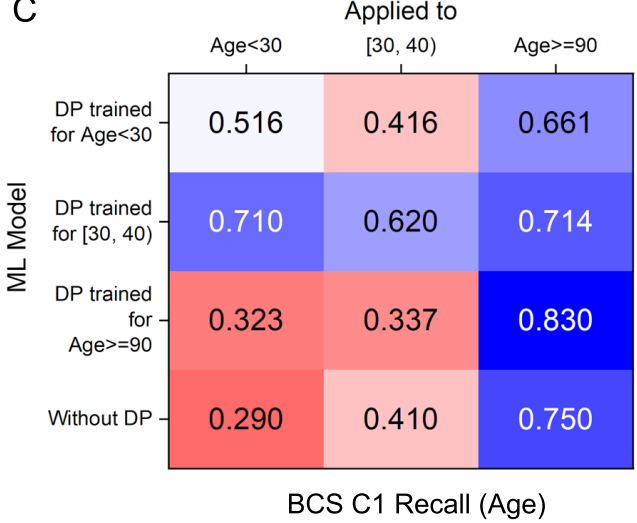

B

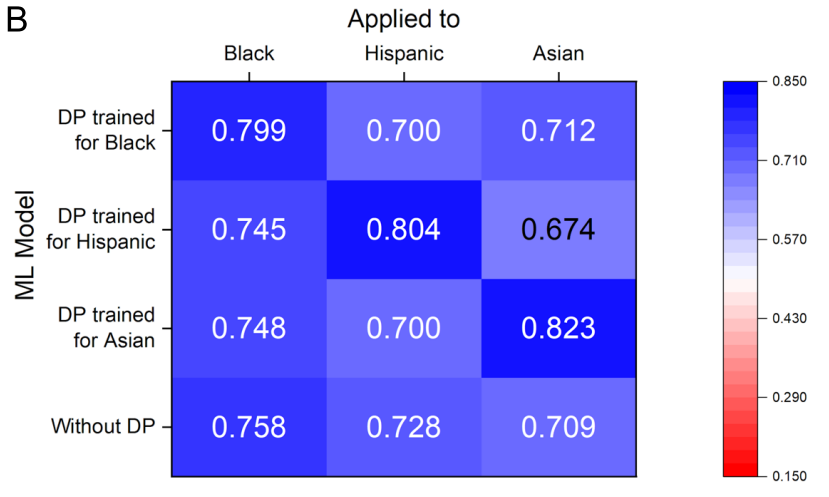

BCS Balanced Accuracy (Race)

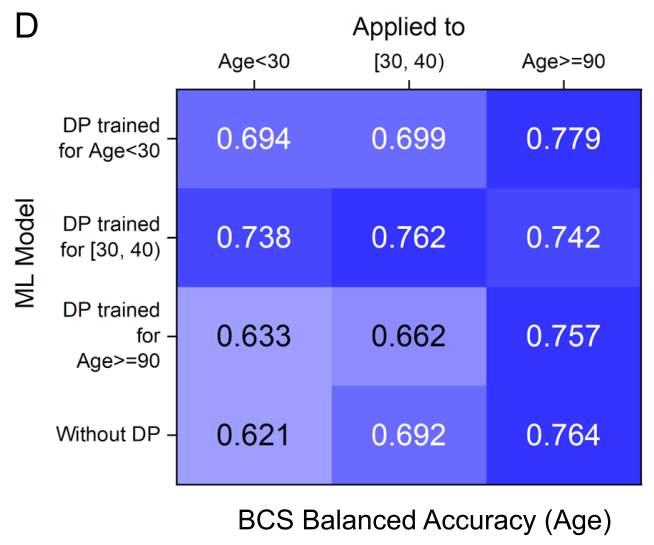

Figure 4: Minority class (C1) recall and balanced accuracy results from cross-group experiments where DP models trained for a specific demographic group is applied to patients of other groups in the 5-year breast cancer survivability (BCS) prediction. DP trained for Black represents the machine learning model for Black patients that is obtained using the DP bias correction method, similarly for Hispanic and Asian. Performance of the original machine learning model without DP or any sampling is also shown. $\mathrm{C} 1$ recalls and balanced accuracies of four trained machine learning models being applied to three races for the BCS prediction are shown in (A) and (B), respectively. Similarly, cross-age-group results for the BCS prediction are shown in (C) and (D). In all DP rows (except $<30$ ), highest values are where the race/age group of patients being predicted on matches the race/age group that the DP model is designed for. 
medRxiv preprint doi: https://doi.org/10.1101/2021.03.26.21254401; this version posted April 23, 2021. The copyright holder for this preprint (which was not certified by peer review) is the author/funder, who has granted medRxiv a license to display the preprint in perpetuity.

It is made available under a CC-BY-NC-ND 4.0 International license.

A

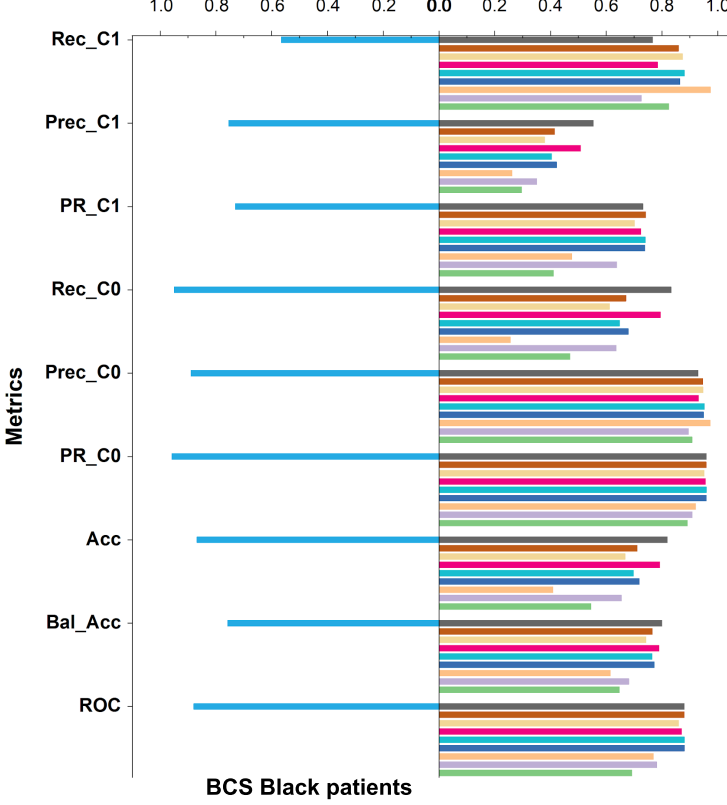

B

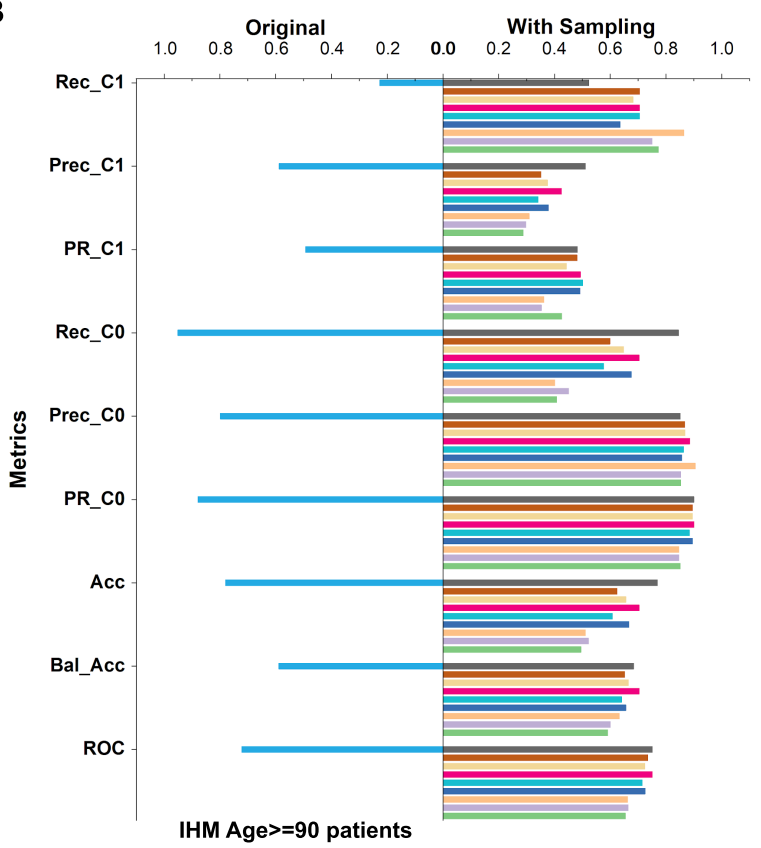

Figure 5: 5-year breast cancer survivability (BCS) prediction for Black patients and in-hospital mortality (IHM) prediction for age group 90+ under various sampling conditions, including DP and the original machine learning model without any sampling. (A) Prediction results from the original model (left) and different sampling models (right) for Black patients in the BCS prediction with the SEER dataset. (B) Prediction results from the original model (left) and different sampling models (right) for age group $90+$ in the IHM prediction with the MIMIC III dataset. 
A

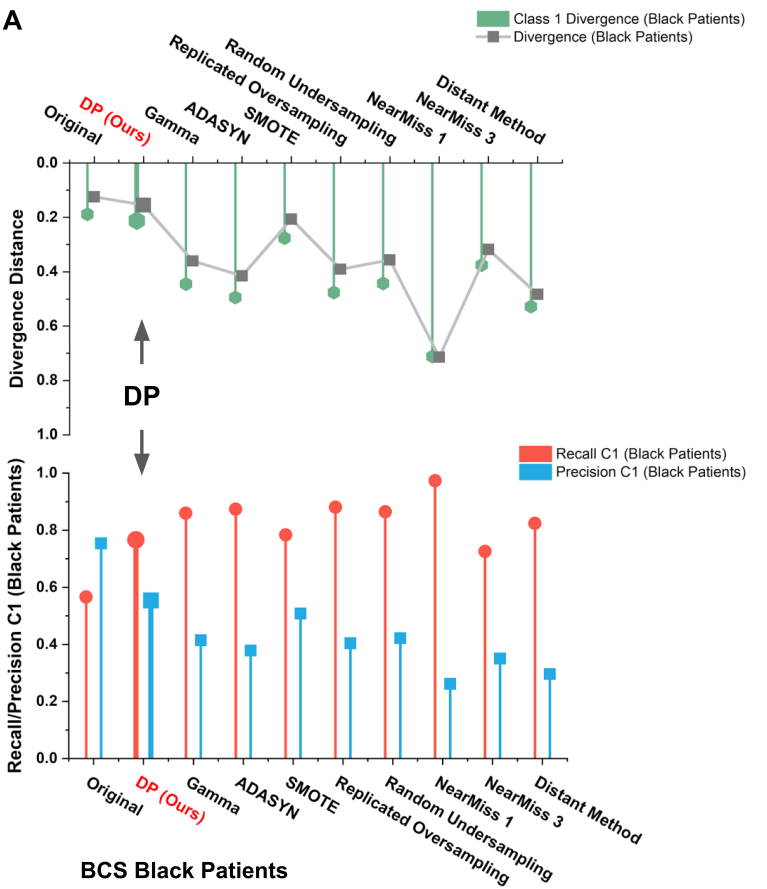

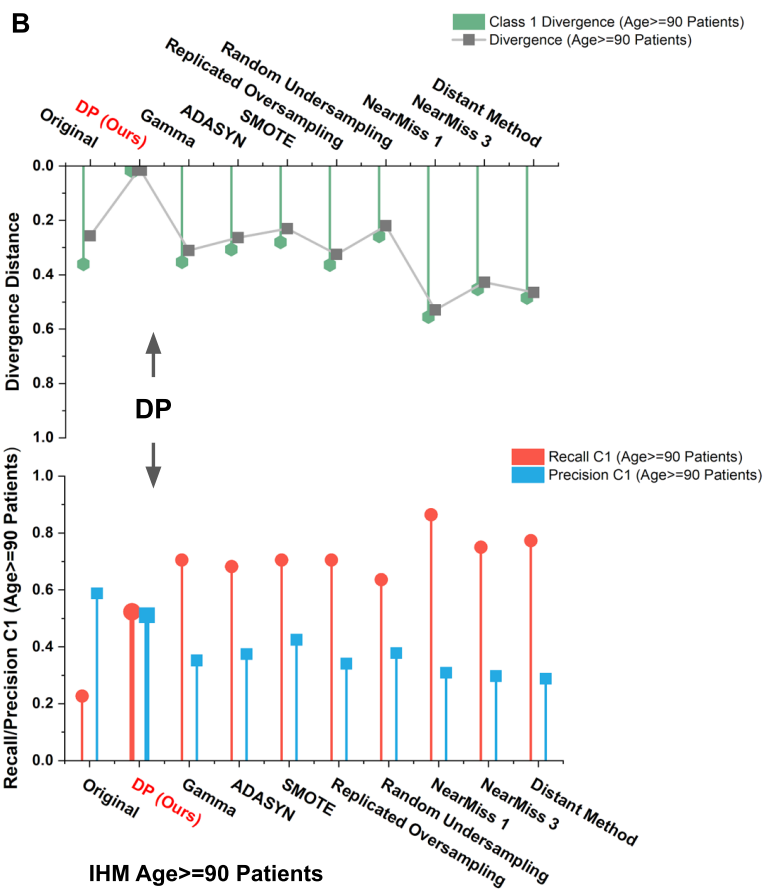

Figure 6: Divergence scores and Class 1 (C1) recall and precision values under various sampling conditions for 5-year breast cancer survivability (BCS) prediction with the SEER dataset and inhospital mortality (IHM) prediction with the MIMIC III dataset. Divergence represents the difference in precision and recall score. A low divergence score with a high recall is desirable. Original represents the original machine learning without any bias correction. (A) Divergence scores (top) and C1 precision and recall (bottom) for Black patients in the BCS prediction. (B) Divergence scores (top) and C1 precision and recall (bottom) for age group 90+ in the IHM prediction. 
medRxiv preprint doi: https://doi.org/10.1101/2021.03.26.21254401; this version posted April 23, 2021. The copyright holder for this preprint (which was not certified by peer review) is the author/funder, who has granted medRxiv a license to display the preprint in perpetuity.

\section{References}

1 Parisot S, Ktena SI, Ferrante E, et al. Disease prediction using graph convolutional networks: application to autism spectrum disorder and Alzheimer's disease. Medical image analysis 2018; 48: 11730 .

2 Malav A, Kadam K, Kamat P. Prediction of heart disease using k-means and artificial neural network as Hybrid Approach to Improve Accuracy. International Journal of Engineering and Technology 2017; 9(4): 3081-5.

3 Bora A, Balasubramanian S, Babenko B, et al. Predicting the risk of developing diabetic retinopathy using deep learning. The Lancet Digital Health 2020; published online November 26. https://doi.org/10.1016/S2589-7500(20)30250-8.

4 Ten Haaf K, Jeon J, Tammemägi MC, et al. Risk prediction models for selection of lung cancer screening candidates: A retrospective validation study. PLoS Med 2017; 14(4): e1002277.

$5 \quad$ Hegselmann S, Gruelich L, Varghese J, Dugas M. Reproducible Survival Prediction with SEER Cancer Data. Machine Learning for Healthcare Conference 2018: 49-66.

6 Tandy-Connor S, Guiltinan J, Krempely K, et al. False-positive results released by direct-toconsumer genetic tests highlight the importance of clinical confirmation testing for appropriate patient care. Genetics in Medicine 2018; 20(12): 1515-21.

7 Augusto JB, Davies RH, Bhuva AN, et al. Diagnosis and risk stratification in hypertrophic cardiomyopathy using machine learning wall thickness measurement: a comparison with human testretest performance. The Lancet Digital Health 2020; published online December 3. https://doi.org/10.1016/S2589-7500(20)30267-3.

8 Raket LL, Jaskolowski J, Kinon BJ, et al. Dynamic ElecTronic hEalth reCord deTection (DETECT) of Individuals at Risk of a First Episode of Psychosis: A Case-Control Development and Validation Study. The Lancet Digital Health 2020; 2: e229-39.

9 Pullano G, Valdano E, Scarpa N, Rubrichi S, Colizza V. Evaluating the Effect of Demographic Factors, Socioeconomic Factors, and Risk Aversion on Mobility During the COVID-19 Epidemic in France Under Lockdown: A Population-based Study. Lancet Digit Health 2020; 2(12): e638-e49. 10 Gauher S, Boylu F. Cleveland Clinic to Identify At-Risk Patients in ICU using Cortana Intelligence. Microsoft 2016; published online September 26. https://docs.microsoft.com/enus/archive/blogs/machinelearning/cleveland-clinic-to-identify-at-risk-patients-in-icu-using-cortanaintelligence-suite (accessed December 15, 2020).

11 Command Center to Improve Patient Flow. Johns Hopkins Medicine 2016; published online March 1. https://www.hopkinsmedicine.org/news/articles/command-center-to-improve-patient-flow (accessed December 15, 2020).

12 Awad A, Bader-El-Den M, McNicholas J, Briggs J. Early hospital mortality prediction of intensive care unit patients using an ensemble learning approach. International Journal of Medical Informatics 2017; 108: 185-95.

13 Sennaar K. How America's 5 Top Hospitals are Using Machine Learning Today. Emerj 2020; published online March 24. https://emerj.com/ai-sector-overviews/top-5-hospitals-using-machinelearning/ (accessed December 15, 2020)

14 Harutyunyan H, Khachatrian H, Kale DC, Ver Steeg G, Galstyan A. Multitask learning and benchmarking with clinical time series data. Scientific Data 2019; 6(1): 1-18.

15 Johnson AE, Pollard TJ, Mark RG. Reproducibility in critical care: a mortality prediction case study. Machine Learning for Healthcare Conference 2017: 361-76.

16 Bejnordi BE, Veta M, Van Diest PJ, et al. Diagnostic assessment of deep learning algorithms for detection of lymph node metastases in women with breast cancer. JAMA 2017; 318(22): 2199-210.

17 Johnson JM, Khoshgoftaar TM. Survey on deep learning with class imbalance. Journal of Big Data 2019; 6(1):1-54.

18 Obermeyer Z, Powers B, Vogeli C, Mullainathan S. Dissecting racial bias in an algorithm used to manage the health of populations. Science 2019; 366(6464): 447-53. 
medRxiv preprint doi: https://doi.org/10.1101/2021.03.26.21254401; this version posted April 23, 2021. The copyright holder for this preprint (which was not certified by peer review) is the author/funder, who has granted medRxiv a license to display the preprint in perpetuity. It is made available under a CC-BY-NC-ND 4.0 International license .

19 Pierson E, Cutler DM, Leskovec J, Mullainathan S, Obermeyer Z. An algorithmic approach to reducing unexplained pain disparities in underserved populations. Nature Medicine 2021; 27(1): 136-40. 20 Yong E. A Popular Algorithm Is No Better at Predicting Crimes Than Random People. The Atlantic 2018; published online January 17.

https://www.theatlantic.com/technology/archive/2018/01/equivant-compas-algorithm/550646/ (accessed December 20, 2020).

21 Dressel J, Farid H. The accuracy, fairness, and limits of predicting recidivism. Science Advances 2018; 4(1): eaao5580.

22 Angwin J, Larson J, Mattu S, Kirchner L. Machine Bias: There's software used across the country to predict future criminals and it's biased against blacks. PROPUBLICA 2016; published online May 23. https://www.propublica.org/article/machine-bias-risk-assessments-in-criminal-sentencing (accessed December 15, 2020).

23 Sweeney L. Discrimination in Online Ad Delivery. Queue 2013; 11(3): 10-29.

24 Dastin J. Amazon scraps secret AI recruiting tool that showed bias against women. REUTERS

2018; published online October 10. https://www.reuters.com/article/us-amazon-com-jobs-automationinsight/amazon-scraps-secret-ai-recruiting-tool-that-showed-bias-against-women-idUSKCN1MK08G (accessed December 15 2020).

25 Buolamwini J, Gebru T. Gender Shades: Intersectional Accuracy Disparities in Commercial Gender Classification. In: Sorelle AF, Christo W, editors. Proceedings of the 1st Conference on Fairness, Accountability and Transparency. PMLR 2018: 77-91.

26 Wilkinson J, Arnold KF, Murray EJ, van Smeden M, Carr K, Sippy R, de Kamps M, Beam A, Konigorski S, Lippert C, Gilthorpe MS. Time to reality check the promises of machine learning-powered precision medicine. The Lancet Digital Health 2020; published online September 16. https://doi.org/10.1016/S2589-7500(20)30200-4.

27 Van Hulse J, Khoshgoftaar T, Napolitano A. Experimental Perspectives on Learning from Imbalanced Data. Proceedings of the 24th international conference on Machine learning 2007: 935-942. 28 Mani I, Zhang I. kNN Approach to Unbalanced Data Distributions: A Case Study Involving Information Extraction. Proceedings of Workshop on Learning from Imbalanced Datasets 2003.

29 Chawla NV, Bowyer KW, Hall LO, Kegelmeyer WP. SMOTE: synthetic minority over-sampling technique. J Artif Int Res 2002; 16(1): 321-57.

30 He H, Bai Y, Garcia EA, Li S. ADASYN: Adaptive synthetic sampling approach for imbalanced learning. IEEE International Joint Conference on Neural Networks 2008: 1322-8.

31 Kamalov F, Denisov D. Gamma distribution-based sampling for imbalanced data. KnowledgeBased Systems 2020; 207: 106368.

32 Johnson AEW, Pollard TJ, Shen L, et al. MIMIC-III, a freely accessible critical care database. Scientific Data 2016; 3(1): 160035.

33 Galatzer-Levy IR, Karstoft KI, Statnikov A, Shalev AY. Quantitative forecasting of PTSD from early trauma responses: A machine learning application. J Psychiatr Res. 2014 Dec; 59: 68-76.

34 Galatzer-Levy IR, Bonanno GA, Bush DEA, LeDoux JE. Heterogeneity in threat extinction learning: substantive and methodological considerations for identifying individual difference in response to stress. Front. Behav. Neurosci. 2013. 7.

35 SEER Incidence Data, 1975 - 2017. National Cancer Institute, Surveillance, Epidemiology, and End Results Program. https://seer.cancer.gov/data/

36 Lee SB, Oh JH, Park JH, Choi SP, Wee JH. Differences in youngest-old, middle-old, and oldestold patients who visit the emergency department. Clin Exp Emerg Med. 2018 Dec; 5(4): 249-255.

372017 Profile of Older Americans. Administration for Community Living. 2018. Available at: https://acl.gov/sites/default/files/Aging\%20and\%20Disability\%20in\%20America/2017OlderAmericansPr ofile.pdf

38 Mukherjee P, Zhou M, Lee E, Schicht A, Balagurunathan Y, Napel S, Gillies R, Wong S, Thieme A, Leung A, Gevaert O. A shallow convolutional neural network predicts prognosis of lung cancer 
medRxiv preprint doi: https://doi.org/10.1101/2021.03.26.21254401; this version posted April 23, 2021. The copyright holder for this preprint (which was not certified by peer review) is the author/funder, who has granted medRxiv a license to display the preprint in perpetuity.

It is made available under a CC-BY-NC-ND 4.0 International license .

patients in multi-institutional computed tomography image datasets. Nature Machine Intelligence 2020. 2: 274-282.

39 Miikkulainen R, Forrest S. A biological perspective on evolutionary computation. Nature Machine Intelligence 2021. 3: 9-15.

40 Yuan W, et al. Temporal bias in case-control design: preventing reliable predictions of the future. Nature Communications 2021. 12, Article number: 1107. 
medRxiv preprint doi: https://doi.org/10.1101/2021.03.26.21254401; this version posted April 23, 2021. The copyright holder for this preprint (which was not certified by peer review) is the author/funder, who has granted medRxiv a license to display the preprint in perpetuity.

\title{
Supplementary Information
}

\author{
Subpopulation-specific Machine Learning Prognosis for Underrepresented Patients \\ with Double Prioritized Bias Correction
}

Sharmin Afrose*, Wenjia Song ${ }^{*}$, Charles B. Nemeroff, Chang Lu, Danfeng (Daphne) Yao ${ }^{\#}$

Department of Computer Science, Virginia Tech, Blacksburg, VA, USA (S Afrose BS, W Song BS, D Yao PhD); Department of Psychiatry and Behavioral Sciences, the University of Texas at Austin Dell Medical School, Austin, TX, USA (CB Nemeroff MD PhD); Department of Chemical Engineering, Virginia Tech, Blacksburg, VA, USA (C Lu PhD)

${ }^{*}$ Contributed equally

\#Corresponding Author: Danfeng (Daphne) Yao, Department of Computer Science, Virginia Tech, Blacksburg, VA 24060, USA. danfeng@vt.edu; +1 (540) 553-5964

\section{Supplementary Methods}

Supplementary Table 1: Learning Parameters for Four Prediction Models

\begin{tabular}{|l|c|c|c|c|}
\hline $\begin{array}{l}\text { Learning } \\
\text { Parameter }\end{array}$ & BCS Prediction & IHM Prediction & LCS Prediction & Decomp Prediction \\
\hline Hidden layers & $(20,20)$ & $(16,16)$ & $(20,20)$ & $(128)$ \\
ANN & MLP & LSTM & MLP & LSTM \\
Learning Rate & 0.001 & 0.001 & 0.001 & 0.001 \\
Optimizer & adam & adam & adam & adam \\
Dropout & 0.1 & 0.3 & 0.1 & 0.0 \\
\hline
\end{tabular}

$\mathrm{BCS}=$ Breast cancer survivability; IHM= In hospital mortality; LCS=Lung cancer survivability; Decomp $=$ Decompensation

ANN $=$ Artificial Neural Network

For the IHM prediction task with MIMIC III datasets, training involves 100 epochs or stops early based on validation performance. For DP, we run for 50 epochs up to 20 additional specific minority units. For the Decomp prediction task with MIMIC III datasets, training involves 50 epochs or stops early based on validation performance. For DP experiments, we run for 5 epochs up to 20 additional specific minority units. The SEER cancer dataset is smaller, thus for the cancer prediction tasks, we run 20 epochs for the original code and 6 epochs for sampling experiments. Each epoch produces a machine learning model; to choose the final model, we first identify the top three models based on balanced accuracy and then select the one with the highest precision-recall curve value of the minority class (denoted as PR_C1). 
medRxiv preprint doi: https://doi.org/10.1101/2021.03.26.21254401; this version posted April 23, 2021. The copyright holder for this preprint

(which was not certified by peer review) is the author/funder, who has granted medRxiv a license to display the preprint in perpetuity.

It is made available under a CC-BY-NC-ND 4.0 International license .

For random undersampling technique, we randomly select the majority samples for three times and build models from these three training datasets. We use soft voting ensemble technique to average the result from the models. For SEER dataset, $80 \%$ is used for training and 10\% for testing. Following Hegselmann et $a .^{5}$, our results reported are validation results. For MIMIC III, the percentages are $70 \%$ for training, $15 \%$ for validation, and $15 \%$ for testing.

\section{$\underline{\text { Supplementary Equations }}$}

BCS Class 1: Patient does not survive more than 5 years after breast cancer diagnosis;

IHM Class 1: Based on the first 48 hours ICU information, patient dies in ICU

LCS Class 1: Patient survives more than 5 years after lung cancer diagnosis

Decomp Class 1: Patient's health deteriorates after 24 hours

Recall C1 or Sensitivity $=\frac{\# \text { Predicted True Class } 1}{\# \text { True Class } 1}$
Recall C0 or Specificity $=\frac{\# \text { Predicted True Class } 0}{\# \text { True Class } 0}$

Precision C1 or Positive Predictive Value $=\frac{\# \text { Predicted True Class } 1}{\# \text { Predicted Class } 1}$

Precision C0 or Negative Predictive Value $=\frac{\# \text { Predicted True Class } 0}{\# \text { Predicted Class } 0}$

Accuracy $=\frac{\# \text { Predicted True Class } 1+\# \text { Predicted True Class } 0}{\text { \#True Class } 1+\text { \#True Class } 0}$

Balanced Accuracy $=\frac{\text { Recall C1 }+ \text { Recall } C 0}{2}$

F1-Score $C 1=2 * \frac{\text { Precision } C 1 * \text { Recall } C 1}{\text { Precision } C 1+\text { Recall } C 1}$

F1-Score CO $=2 * \frac{\text { Precision } C 0 * \text { Recall C0 }}{\text { Precision } C 0+\text { Recall } C 0}$

Divergence $=\frac{\mid \text { Recall C1 }- \text { Precision } C 1|+| \text { Recall C } 0-\text { Precision } C 0 \mid}{2}$

Divergence $C 1=\frac{\mid \text { Recall } C 1-\text { Precision } C 1 \mid}{2}$

Divergence $C O=\frac{\mid \text { Recall C0 }- \text { Precision C0 } \mid}{2}$ 
medRxiv preprint doi: https://doi.org/10.1101/2021.03.26.21254401; this version posted April 23, 2021. The copyright holder for this preprint (which was not certified by peer review) is the author/funder, who has granted medRxiv a license to display the preprint in perpetuity.

It is made available under a CC-BY-NC-ND 4.0 International license .

\section{Supplementary Figures and Tables}

Supplementary Figure S1: Prediction results under the original machine learning models (no bias correction) and training data statistics for the 5-year lung cancer survivability (LCS) and the decompensation tasks. Rec_C1, Prec_C1, PR_C1, Rec_C0, Prec_C0, PR_C0, Acc, Bal_Acc, ROC stand for Recall Class 1, Precision Class 1, Area Under the Precision-Recall Curve Class 1, Recall Class 0, Precision Class 0, Area Under the PrecisionRecall Curve Class 0, Accuracy, Balanced Accuracy, Area under the ROC Curve, respectively. (A) Prediction class, racial, gender, age group distribution, and prediction results for the LCS prediction. The minority Class 1 represents patients who survive lung cancer for at least 5 years after the diagnosis. (B) Statistics of SEER LCS dataset. (C) Prediction class, racial, gender, age group distribution, and prediction results for the decompensation prediction. The minority Class 1 represents patients whose health deteriorates after 24 hours. (D) Statistics of MIMIC III decompensation dataset.

A

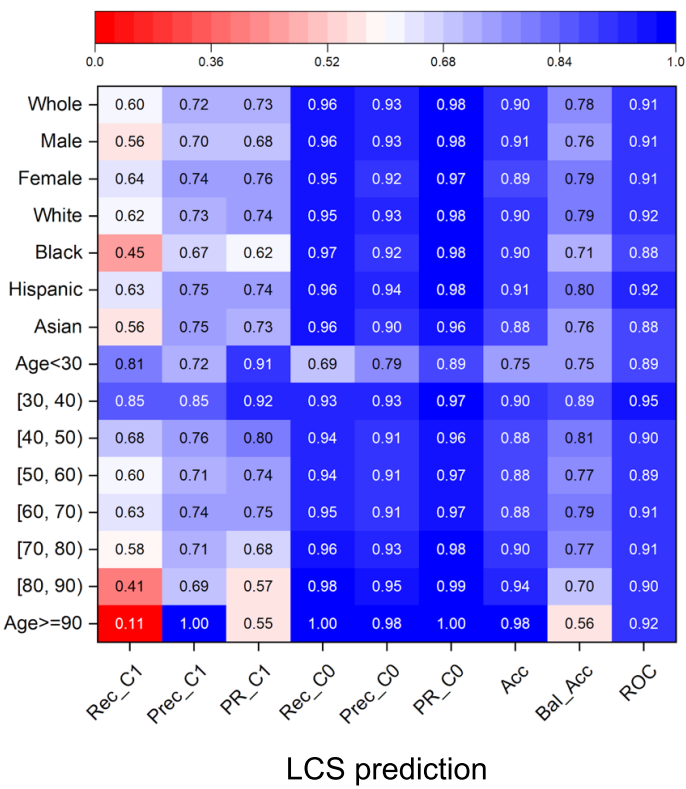

C

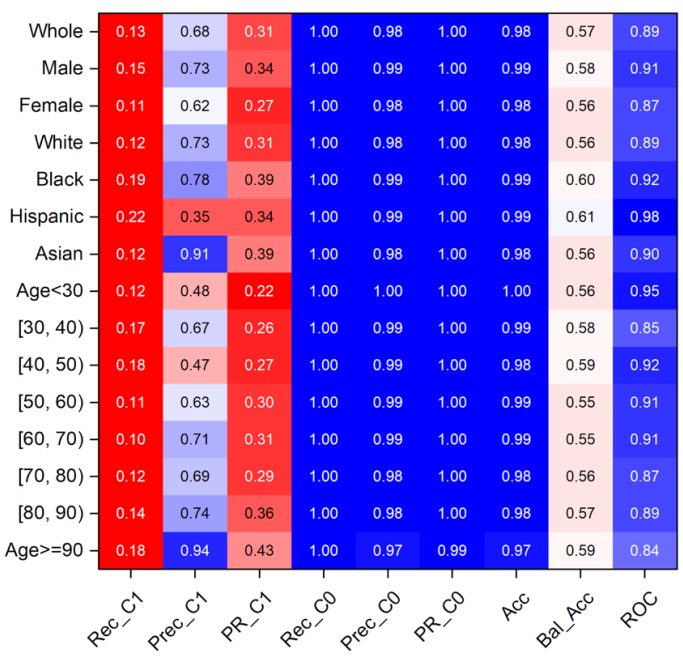

Decompensation prediction
B
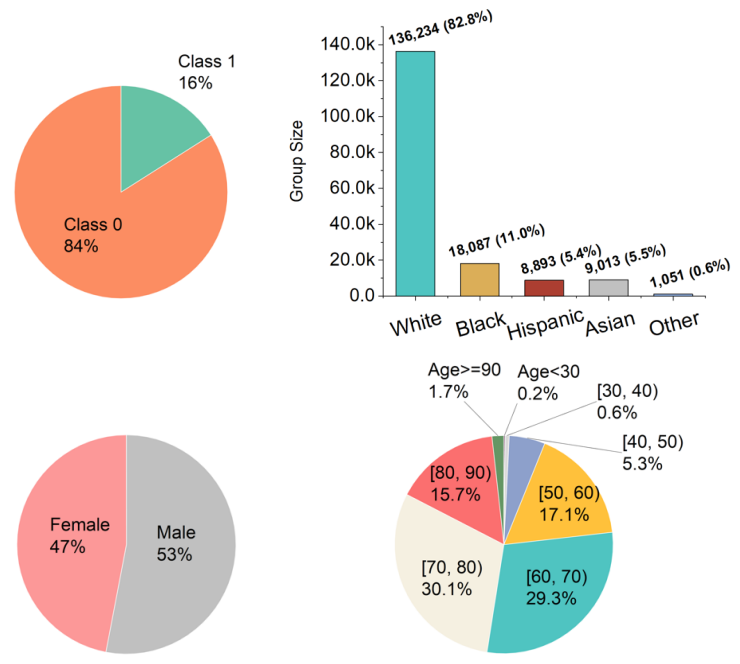

Age $>=90 \quad$ Age $<30$

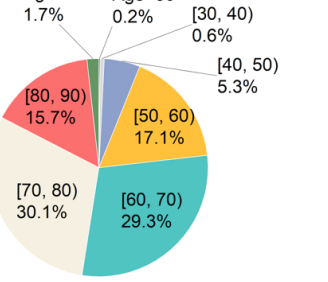

SEER dataset statistics for LCS

D
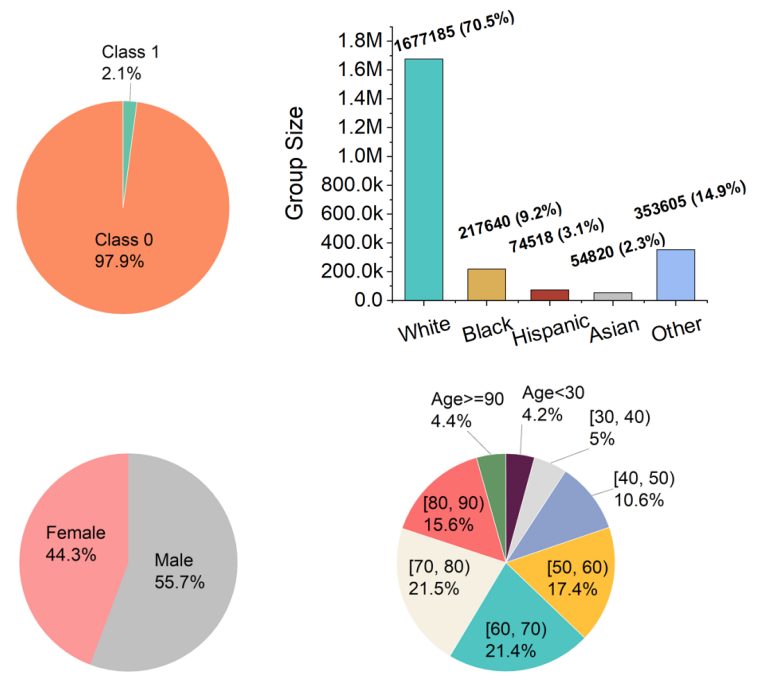

MIMIC dataset statistics for Decompensation 
medRxiv preprint doi: https://doi.org/10.1101/2021.03.26.21254401; this version posted April 23, 2021. The copyright holder for this preprint (which was not certified by peer review) is the author/funder, who has granted medRxiv a license to display the preprint in perpetuity.

It is made available under a CC-BY-NC-ND 4.0 International license .

Supplementary Table 2: Breast Cancer Survivability (BCS) prediction results with the SEER dataset on 6 minority demographic groups for the original model and the DP model. The added DP units column shows the optimal number of additional units of specific $\mathrm{C} 1$ subgroup samples in DP bias correction. All $\mathrm{C} 1$ percentages and numbers refer to the training datasets. Testing dataset is not sampled.

\begin{tabular}{|l|c|c|c|c|c|c|c|}
\hline \multirow{2}{*}{$\begin{array}{l}\text { Minority } \\
\text { Demographic } \\
\text { Group }\end{array}$} & \multicolumn{3}{|c|}{ Original Model } & \multicolumn{3}{c|}{ With DP Bias Correction } \\
\cline { 2 - 8 } & C1\% (\#) & Rec. & Prec. & $\begin{array}{c}\text { Added DP } \\
\text { units* }\end{array}$ & C1\% (\#) & Rec. & Prec. \\
\hline Age>=90 & $\begin{array}{l}55.97 \\
(989)\end{array}$ & 0.75 & 0.76 & 2 & $79.23(2967)$ & 0.83 & 0.72 \\
\hline Black & $\begin{array}{c}21.68 \\
(4546)\end{array}$ & 0.57 & 0.75 & 3 & $\begin{array}{c}52.55 \\
(18184)\end{array}$ & 0.77 & 0.55 \\
\hline Age<30 & $\begin{array}{c}18.30 \\
(228)\end{array}$ & 0.29 & 0.60 & 11 & $72.88(2736)$ & 0.52 & 0.5 \\
\hline$[30,40)$ & $\begin{array}{c}13.66 \\
(1448)\end{array}$ & 0.41 & 0.69 & 6 & $\begin{array}{c}52.55 \\
(10136)\end{array}$ & 0.62 & 0.47 \\
\hline Hispanic & $\begin{array}{c}13.38 \\
(2575)\end{array}$ & 0.48 & 0.71 & 4 & $\begin{array}{c}43.57 \\
(12875)\end{array}$ & 0.74 & 0.44 \\
\hline Asian & $\begin{array}{c}8.88 \\
(1312)\end{array}$ & 0.44 & 0.68 & 11 & $\begin{array}{c}53.91 \\
(15744)\end{array}$ & 0.77 & 0.39 \\
\hline
\end{tabular}

* Not including the original unit $\mathrm{C} 1 \%=$ Class 1 percentage of the specific minority demographic in the training dataset 
Supplementary Table 3: In-Hospital Mortality (IHM) prediction results with the MIMIC III dataset on 6 minority demographic groups for the original model and the DP model. The added DP units column shows the optimal number of additional units of specific $\mathrm{C} 1$ subgroup samples in DP bias correction. All $\mathrm{C} 1$ percentages and numbers refer to the training datasets. Testing dataset is not sampled.

\begin{tabular}{|l|c|c|c|c|c|c|c|}
\hline \multirow{2}{*}{$\begin{array}{l}\text { Minority } \\
\text { Demographic } \\
\text { Group }\end{array}$} & \multicolumn{3}{|c|}{ Original Model } & \multicolumn{5}{c|}{ With DP Bias Correction } \\
\cline { 2 - 8 } & C1\% (\#) & Rec. & Prec. & $\begin{array}{c}\text { Added DP } \\
\text { units* }\end{array}$ & C1\% (\#) & Rec. & Prec. \\
\hline Age>=90 & $8.25(164)$ & 0.23 & 0.59 & 11 & $51.91(1968)$ & 0.52 & 0.51 \\
\hline Black & $6.34(126)$ & 0.18 & 0.46 & 3 & $21.31(504)$ & 0.32 & 0.60 \\
\hline$[30,40)$ & $2.87(57)$ & 0.33 & 0.71 & 2 & $8.14(171)$ & 0.40 & 0.50 \\
\hline Asian & $2.62(52)$ & 0.44 & 0.5 & 1 & $5.10(104)$ & 0.44 & 0.57 \\
\hline Hispanic & $2.01(40)$ & 0.5 & 0.57 & 1 & $3.95(80)$ & 0.63 & 0.56 \\
\hline Age $<30$ & $1.96(39)$ & 0.33 & 0.25 & 5 & $10.72(234)$ & 0.33 & 0.25 \\
\hline
\end{tabular}

* Not including the original unit

$\mathrm{C} 1 \%=$ Class 1 percentage of the specific minority demographic in the training dataset 
medRxiv preprint doi: https://doi.org/10.1101/2021.03.26.21254401; this version posted April 23, 2021. The copyright holder for this preprint (which was not certified by peer review) is the author/funder, who has granted medRxiv a license to display the preprint in perpetuity.

It is made available under a CC-BY-NC-ND 4.0 International license .

Supplementary Figure S2: Minority class (C1) recall and balanced accuracy results from the crossgroup experiment where DP models trained for a specific demographic group is applied to patients of other groups in the in-hospital mortality (IHM) prediction. DP trained for Black represents the machine learning model for Black patients that is obtained using the DP bias correction method, similarly for Hispanic and Asian. Performance of the original machine learning model without DP or any sampling is also shown. $\mathrm{C} 1$ recalls and balanced accuracies of four trained machine learning models being applied to three races for the IHM prediction are shown in (A) and (B), respectively. Similarly, cross-age-group results for the IHM prediction are shown in (C) and (D).

A

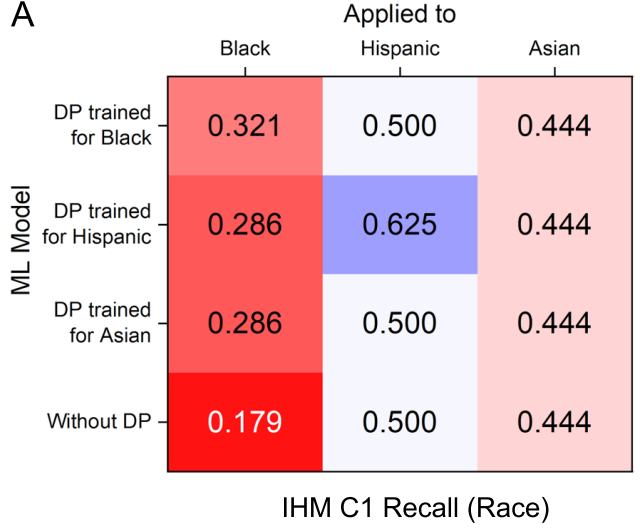

C

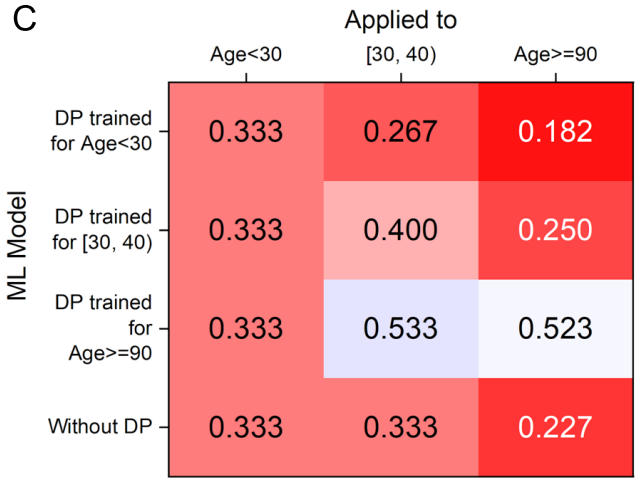

IHM C1 Recall (Age)
B

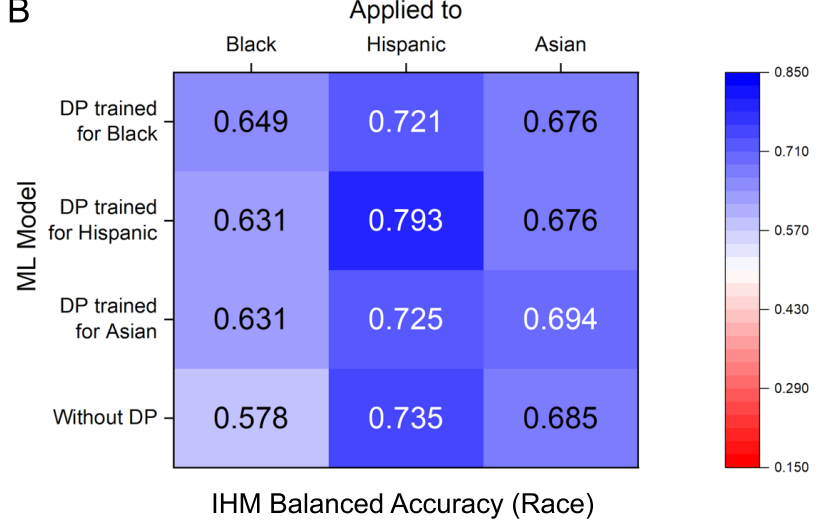

D

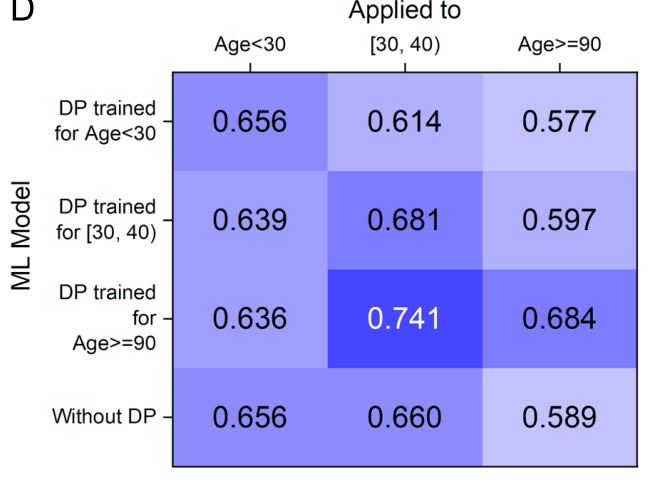

IHM Balanced Accuracy (Age) 
medRxiv preprint doi: https://doi.org/10.1101/2021.03.26.21254401; this version posted April 23, 2021. The copyright holder for this preprint (which was not certified by peer review) is the author/funder, who has granted medRxiv a license to display the preprint in perpetuity.

It is made available under a CC-BY-NC-ND 4.0 International license.

Supplementary Figure S3: 5-year breast cancer survivability (BCS) prediction for age group [30, 40) and in-hospital mortality (IHM) prediction for Black patients under various sampling conditions, including DP and the original machine learning model without any bias correction. (A) Prediction results from the original model (left) and different sampling models (right) for age group [30, $40)$ in the BCS prediction with the SEER dataset. Class 1, representing death 5 years after breast cancer diagnosis, is the minority prediction class. Class 0 , representing survival after 5 years, is the majority class. (B) Prediction results from the original model (left) and different sampling models (right) for Black patients in the IHM prediction with the MIMIC III dataset. Class 1, representing death after staying 48 hours in intensive care units at the hospital, is the minority prediction class. Class 0 , representing survival after staying 48 hours in intensive care units, is the majority prediction class.

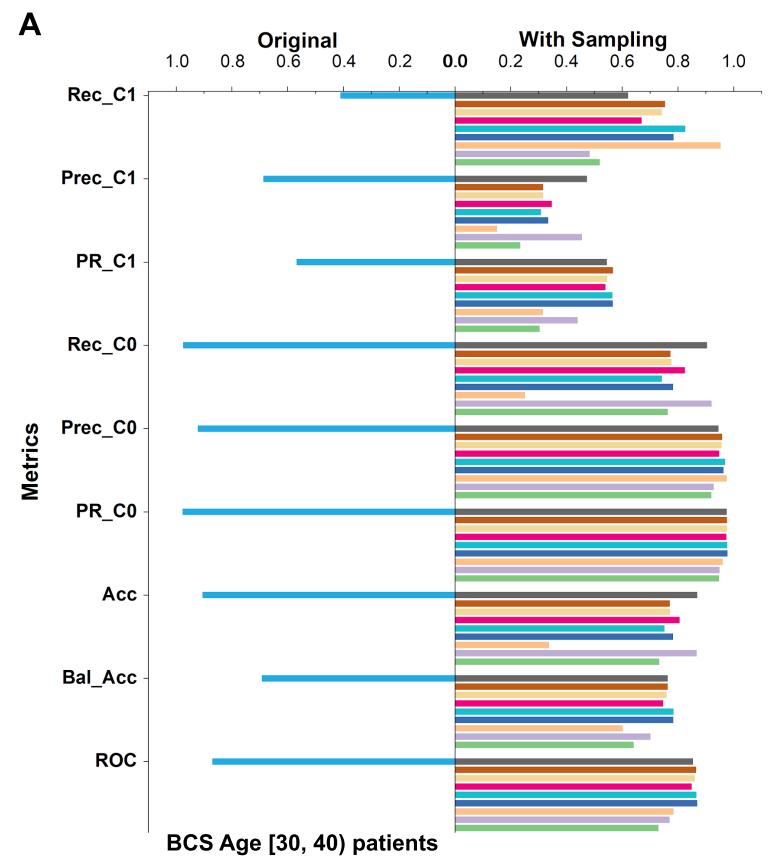

B
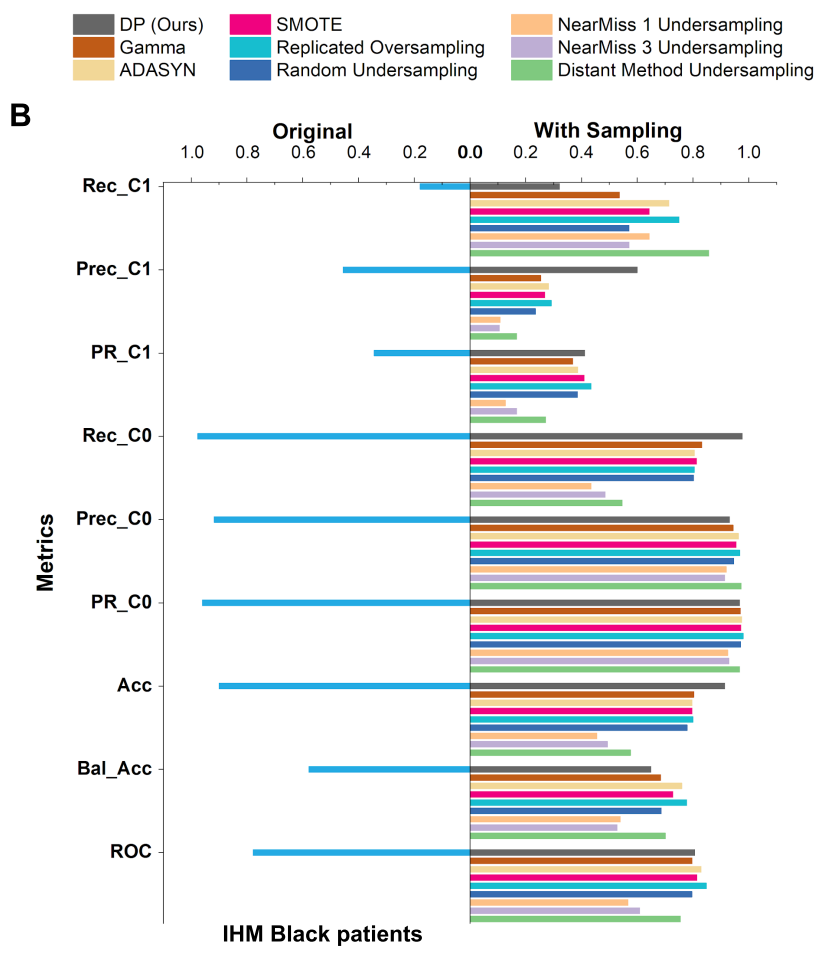
medRxiv preprint doi: https://doi.org/10.1101/2021.03.26.21254401; this version posted April 23, 2021. The copyright holder for this preprint (which was not certified by peer review) is the author/funder, who has granted medRxiv a license to display the preprint in perpetuity.

It is made available under a CC-BY-NC-ND 4.0 International license .

Supplementary Figure S4: Divergence scores and Class 1 (C1) recall and precision values under various sampling conditions for 5-year breast cancer survivability (BCS) prediction with the SEER dataset and in-hospital mortality (IHM) prediction with the MIMIC III dataset. Divergence represents the difference in precision and recall score. A low divergence score with a high recall is desirable. Original represents the original machine learning without any bias correction. (A) Divergence scores (top) and C1 precision and recall (bottom) for age group [30, 40) in the BCS prediction. (B) Divergence scores (top) and $\mathrm{C} 1$ precision and recall (bottom) for Black patients in the IHM prediction.

A

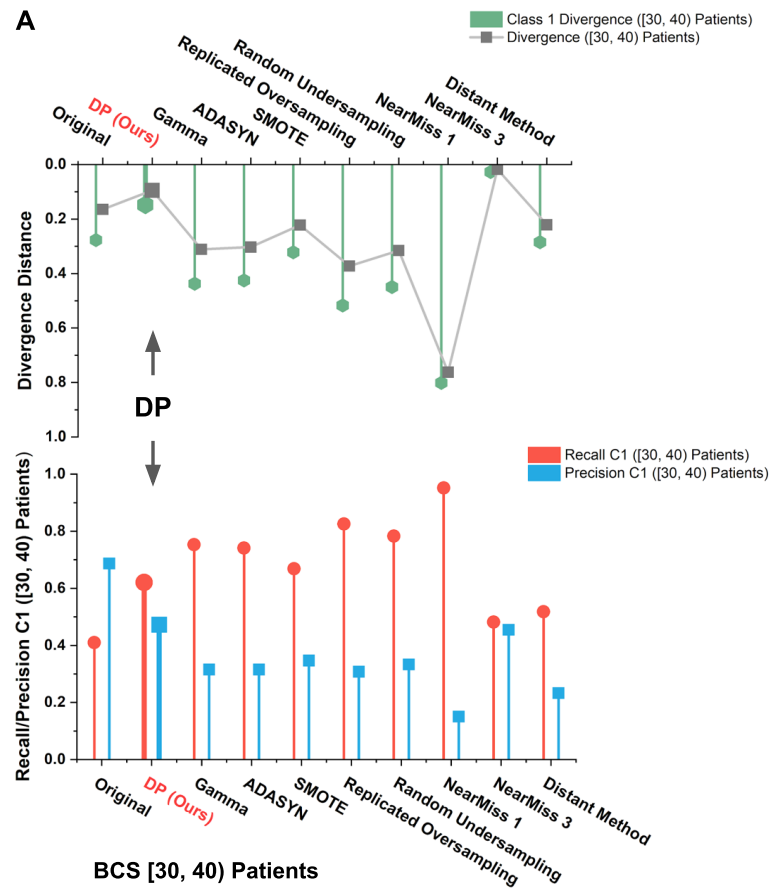

B

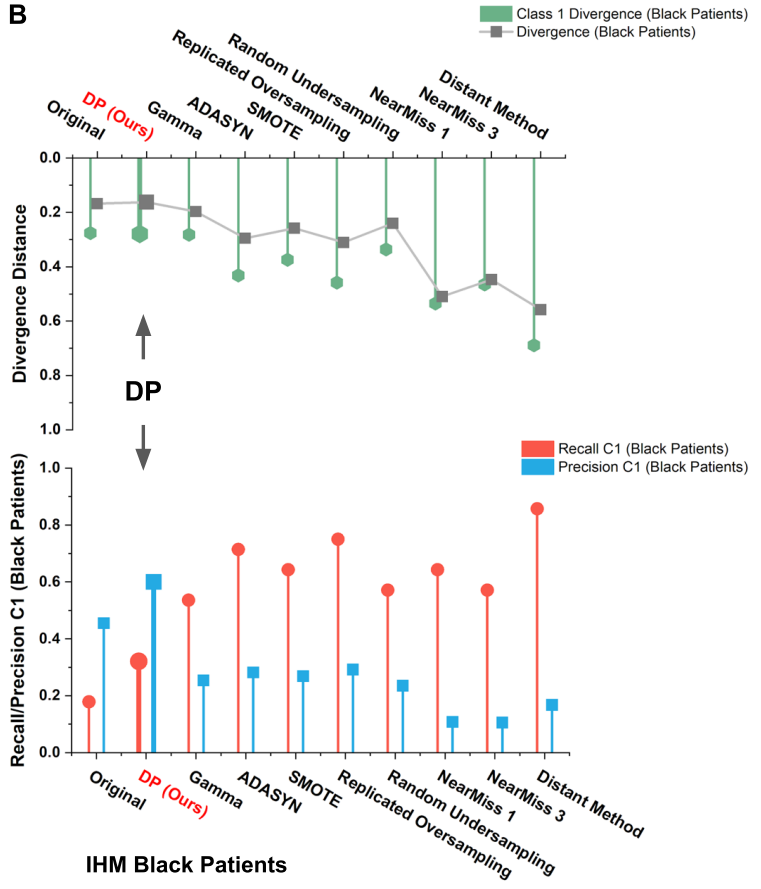


medRxiv preprint doi: https://doi.org/10.1101/2021.03.26.21254401; this version posted April 23, 2021. The copyright holder for this preprint (which was not certified by peer review) is the author/funder, who has granted medRxiv a license to display the preprint in perpetuity.

It is made available under a CC-BY-NC-ND 4.0 International license .

\section{Supplementary Figure S5: Lung cancer survivability (LCS) prediction results under various}

sampling conditions. (A) Prediction results from the original model (left) and different sampling models for Asian patients (right). (B) Prediction results from the original model (left) and different sampling models for age group $[30,40)$ (right).

A

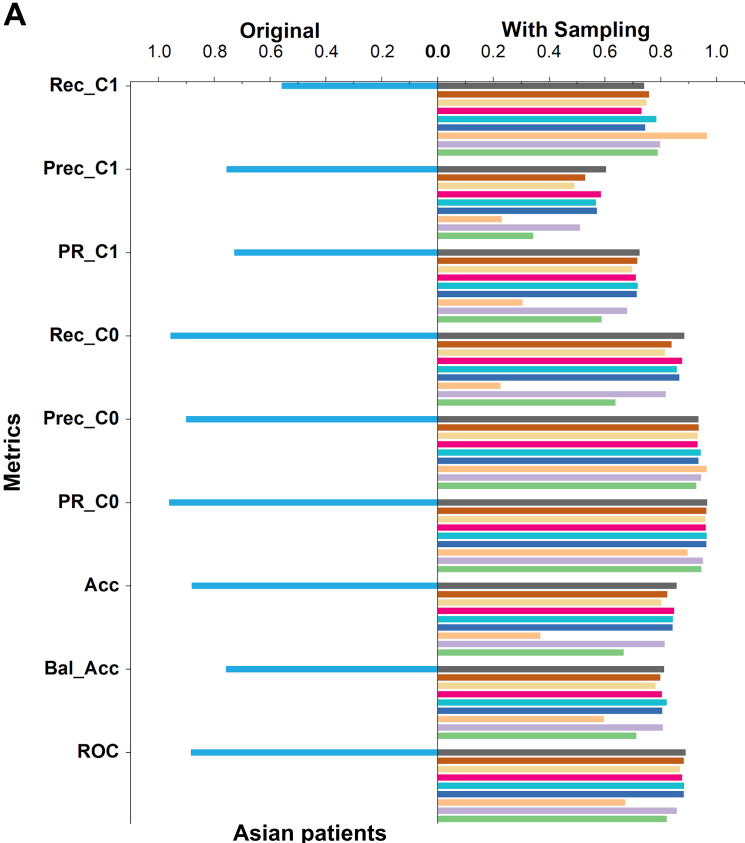

Asian patients
DP (Ours)

Gamma

ADASY

B

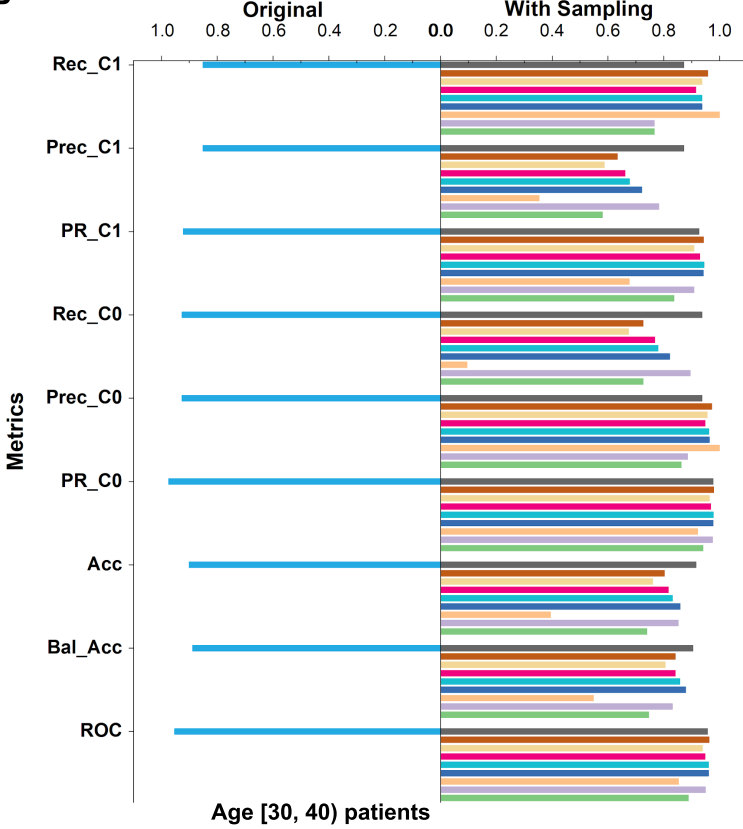


medRxiv preprint doi: https://doi.org/10.1101/2021.03.26.21254401; this version posted April 23, 2021. The copyright holder for this preprint (which was not certified by peer review) is the author/funder, who has granted medRxiv a license to display the preprint in perpetuity.

It is made available under a CC-BY-NC-ND 4.0 International license.

\section{Supplementary Figure S6: Decompensation prediction results under various sampling conditions.}

Because of the large training data size $(2,377,768)$, we have to exclude the sampling methods that require expensive pairwise distance computation. (A) Prediction results from the original model (left) and different sampling models for Black patients (right). (B) Prediction results from the original model (left) and different sampling models for age group 90+ (right).

\section{A}
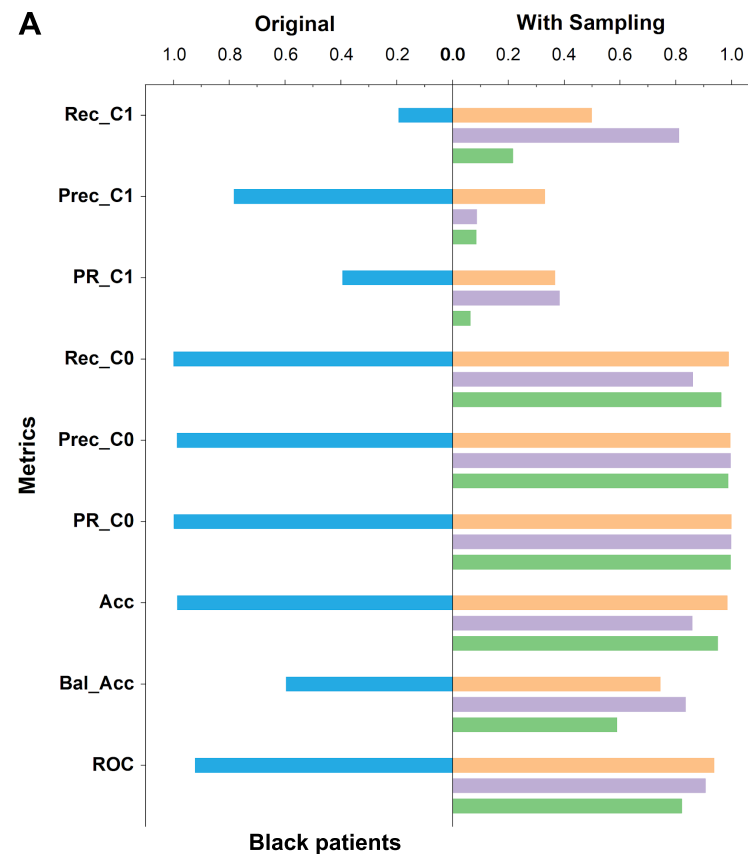

B

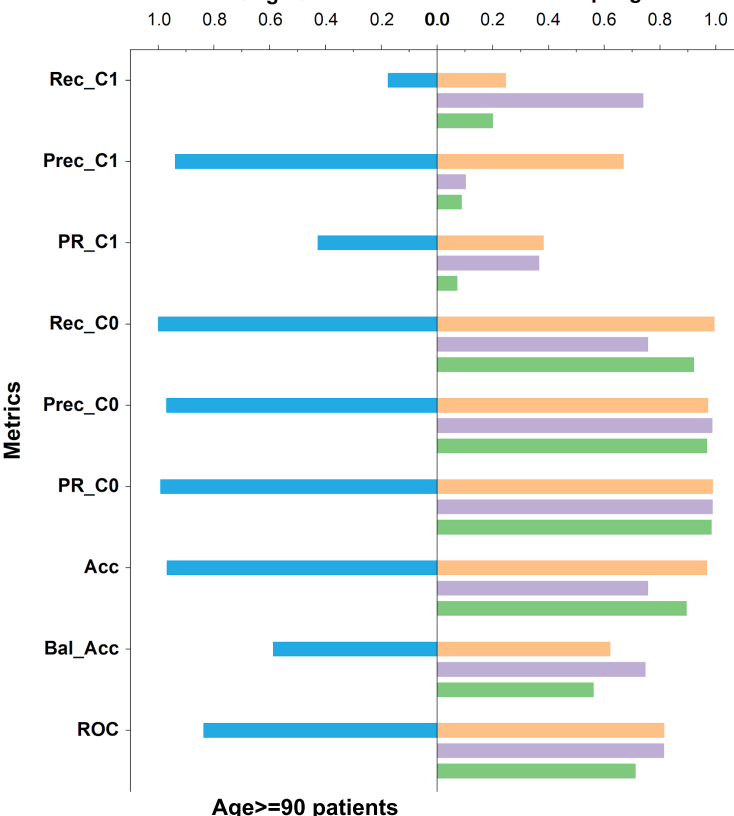


medRxiv preprint doi: https://doi.org/10.1101/2021.03.26.21254401; this version posted April 23, 2021. The copyright holder for this preprint (which was not certified by peer review) is the author/funder, who has granted medRxiv a license to display the preprint in perpetuity.

It is made available under a CC-BY-NC-ND 4.0 International license .

Supplementary Table 4: Lung Cancer Survivability (LCS) prediction results with the SEER dataset on 6 minority demographic groups for the original model and the DP model. The added DP units column shows the optimal number of additional units of specific $\mathrm{C} 1$ subgroup samples in DP bias correction. All $\mathrm{C} 1$ percentages and numbers refer to the training datasets. Testing dataset is not sampled.

\begin{tabular}{|c|c|c|c|c|c|c|c|}
\hline \multirow{2}{*}{$\begin{array}{l}\text { Minority } \\
\text { Demographic } \\
\text { Group }\end{array}$} & \multicolumn{3}{|c|}{$\begin{array}{c}\text { Original Model } \\
\text { w/o DP }\end{array}$} & \multicolumn{4}{|c|}{ With DP Bias Correction } \\
\hline & $\mathrm{C} 1 \%$ & Rec. & Prec. & $\begin{array}{l}\text { Added DP } \\
\text { units* }\end{array}$ & $\mathrm{C} 1 \%$ & Rec. & Prec. \\
\hline Age $<30$ & $\begin{array}{l}63.41 \\
(175)\end{array}$ & 0.813 & 0.722 & 8 & $93.97(1575)$ & 0.875 & 0.737 \\
\hline$[30,40)$ & $\begin{array}{l}33.27 \\
(340)\end{array}$ & 0.851 & 0.851 & 3 & $66.60(1360)$ & 0.872 & 0.872 \\
\hline Asian & $\begin{array}{c}17.97 \\
(1620)\end{array}$ & 0.558 & 0.754 & 6 & $\begin{array}{c}60.53 \\
(11340)\end{array}$ & 0.739 & 0.603 \\
\hline Hispanic & $\begin{array}{c}15.93 \\
(1417)\end{array}$ & 0.632 & 0.748 & 3 & $43.12(5668)$ & 0.787 & 0.604 \\
\hline Black & $\begin{array}{l}13.15 \\
(2378)\end{array}$ & 0.453 & 0.675 & 5 & $\begin{array}{c}47.60 \\
(14268)\end{array}$ & 0.772 & 0.43 \\
\hline Age $>=90$ & $1.64(47)$ & 0.11 & 1 & 4 & $7.67(235)$ & 0.22 & 1 \\
\hline
\end{tabular}

* Not including the original unit $\mathrm{C} 1 \%=$ Class 1 percentage of the specific minority demographic in the training dataset 
medRxiv preprint doi: https://doi.org/10.1101/2021.03.26.21254401; this version posted April 23, 2021. The copyright holder for this preprint (which was not certified by peer review) is the author/funder, who has granted medRxiv a license to display the preprint in perpetuity.

It is made available under a CC-BY-NC-ND 4.0 International license .

Supplementary Table 5: Decompensation prediction results with the MIMIC III dataset on 6 minority demographic groups for the original model and the DP Model. The added DP units column shows the optimal number of additional units of specific $\mathrm{C} 1$ subgroup samples in DP bias correction. All $\mathrm{C} 1$ percentages and numbers refer to the training datasets. Testing dataset is not sampled.

\begin{tabular}{|l|c|c|c|c|c|c|c|}
\hline \multirow{2}{*}{$\begin{array}{l}\text { Minority } \\
\text { Demographic } \\
\text { Group }\end{array}$} & \multicolumn{3}{|c|}{ Original Model } & \multicolumn{3}{c|}{ With DP Bias Correction } \\
\cline { 2 - 8 } & C1\% (\#) & Rec. & Prec. & $\begin{array}{c}\text { Added DP } \\
\text { units* }\end{array}$ & C1\% (\#) & Rec. & Prec. \\
\hline Age>=90 & $\begin{array}{c}7.88 \\
(3884)\end{array}$ & 0.175 & 0.939 & 3 & $\begin{array}{c}25.51 \\
(15536)\end{array}$ & 0.247 & 0.669 \\
\hline Black & $\begin{array}{c}6.84 \\
(3369)\end{array}$ & 0.193 & 0.783 & 15 & $\begin{array}{c}54.01 \\
(53904)\end{array}$ & 0.498 & 0.33 \\
\hline$[30,40)$ & $\begin{array}{c}2.82 \\
(1388)\end{array}$ & 0.166 & 0.667 & 13 & $\begin{array}{c}28.87 \\
(19432)\end{array}$ & 0.237 & 0.265 \\
\hline Asian & $\begin{array}{c}2.75 \\
(1357)\end{array}$ & 0.119 & 0.907 & 15 & $\begin{array}{c}31.19 \\
(21712)\end{array}$ & 0.316 & 0.33 \\
\hline Age<30 & $\begin{array}{c}2.23 \\
(1097)\end{array}$ & 0.117 & 0.478 & 8 & $17.01(9873)$ & 0.298 & 0.134 \\
\hline Hispanic & $\begin{array}{c}2.04 \\
(1005)\end{array}$ & 0.218 & 0.352 & 9 & $\begin{array}{c}17.24 \\
(10050)\end{array}$ & 0.306 & 0.479 \\
\hline
\end{tabular}

* Not including the original unit $\mathrm{C} 1 \%=$ Class 1 percentage of the specific minority demographic in the training dataset 
medRxiv preprint doi: https://doi.org/10.1101/2021.03.26.21254401; this version posted April 23, 2021. The copyright holder for this preprint (which was not certified by peer review) is the author/funder, who has granted medRxiv a license to display the preprint in perpetuity.

It is made available under a CC-BY-NC-ND 4.0 International license.

\section{Supplementary Figure S7: Divergence scores, $\mathrm{C} 1$ recall and precision values under various} sampling conditions for the LCS prediction with the SEER dataset. Divergence represents the difference in precision and recall score. A low divergence score with a high recall is desirable. (A) Divergence scores (top), C1 precision and recall (bottom) for Asian patients. (B) Divergence scores (top), C1 precision and recall (bottom) for [30, 40) age group.
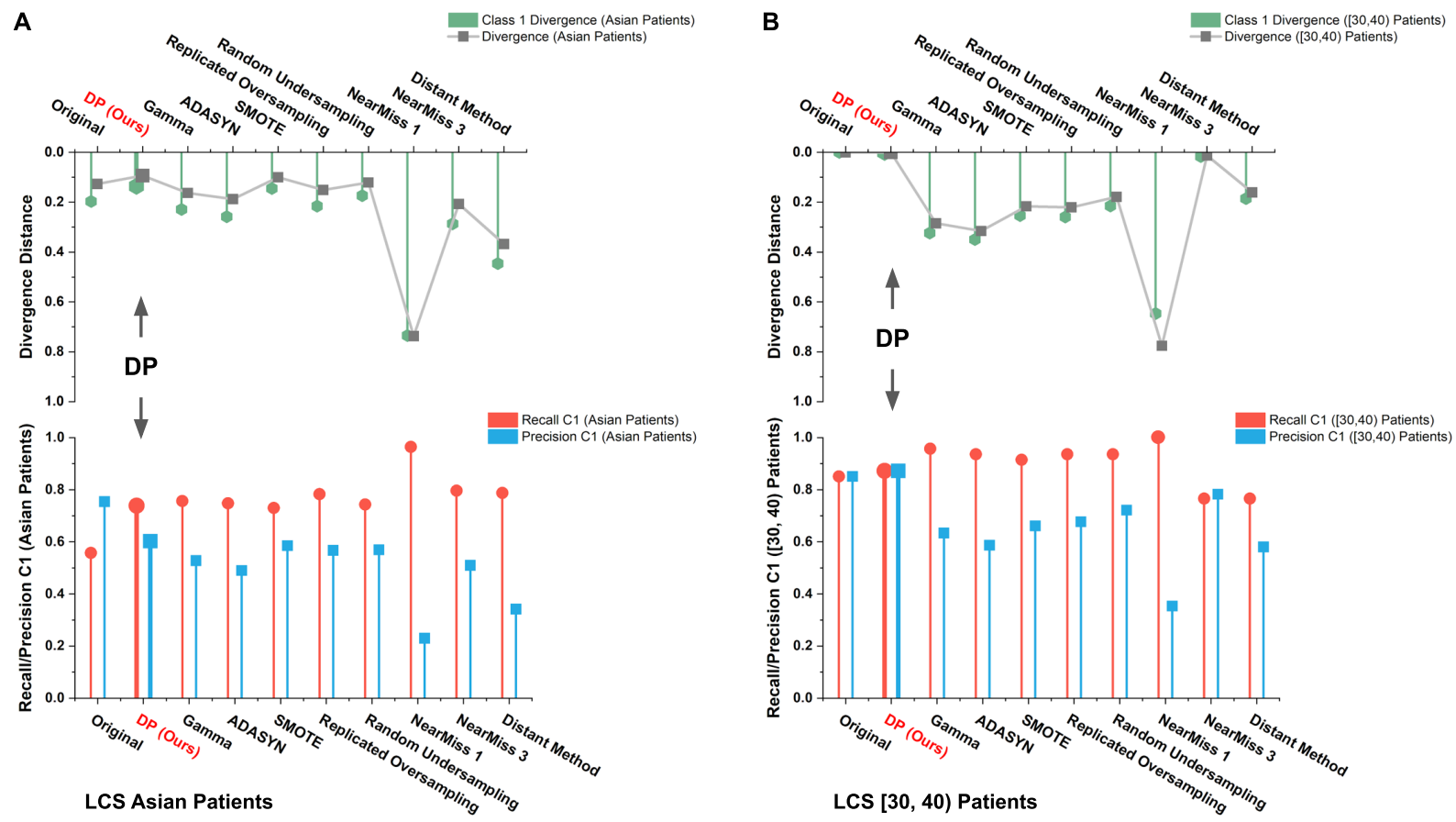
medRxiv preprint doi: https://doi.org/10.1101/2021.03.26.21254401; this version posted April 23, 2021. The copyright holder for this preprint (which was not certified by peer review) is the author/funder, who has granted medRxiv a license to display the preprint in perpetuity.

It is made available under a CC-BY-NC-ND 4.0 International license.

\section{Supplementary Figure S8: Divergence scores, $\mathrm{C} 1$ recall and precision values under various} sampling conditions for the decompensation prediction with the MIMIC III dataset. Because of the large training data size $(2,377,768)$, we have to exclude the sampling methods that require expensive pairwise distance computation. Divergence represents the difference in precision and recall score. A low divergence score with a high recall is desirable. (A) Divergence scores (top), C1 precision and recall (bottom) for Black patients. (B) Divergence scores (top), C1 precision and recall (bottom) for 90+ age group.

A

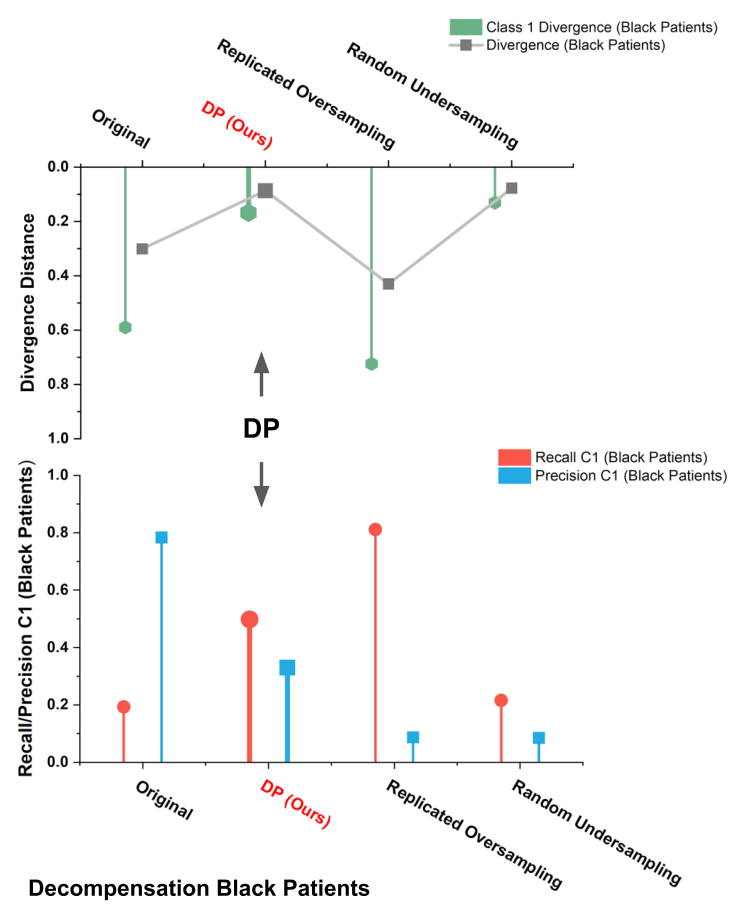

B

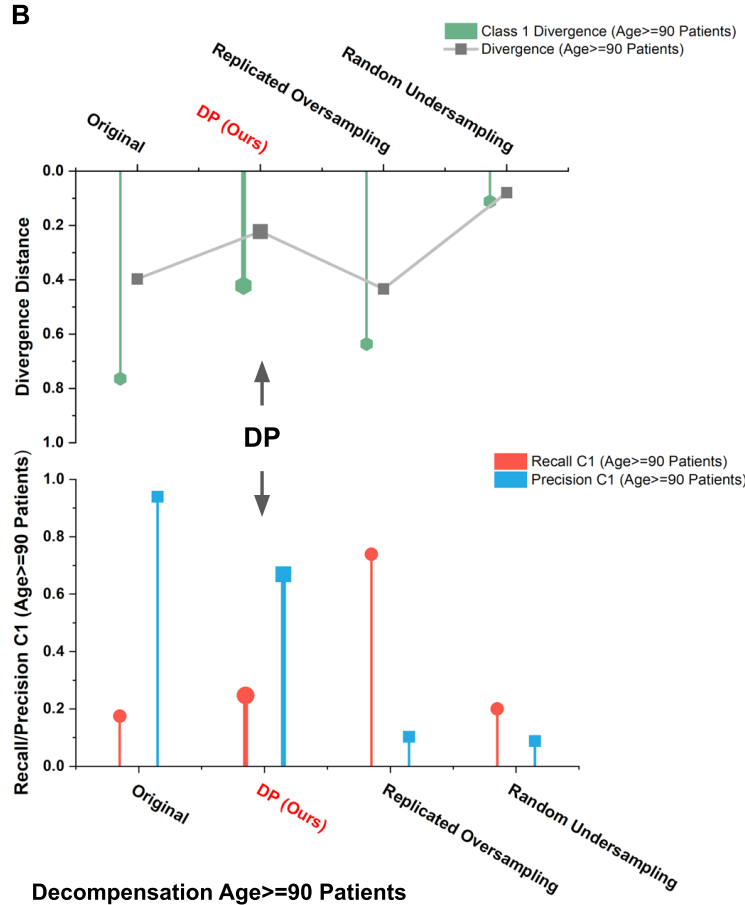


medRxiv preprint doi: https://doi.org/10.1101/2021.03.26.21254401; this version posted April 23, 2021. The copyright holder for this preprint (which was not certified by peer review) is the author/funder, who has granted medRxiv a license to display the preprint in perpetuity.

It is made available under a CC-BY-NC-ND 4.0 International license .

Supplementary Figure S9: Minority class C1 performance, in terms of precision and recall, of six underrepresented demographic subgroups with DP bias correction compared to the original machine learning model without any bias correction in two tasks. (A) The 5-year lung cancer survivability (LCS) prediction with the SEER dataset. (B) The decompensation prediction with the MIMIC III dataset.
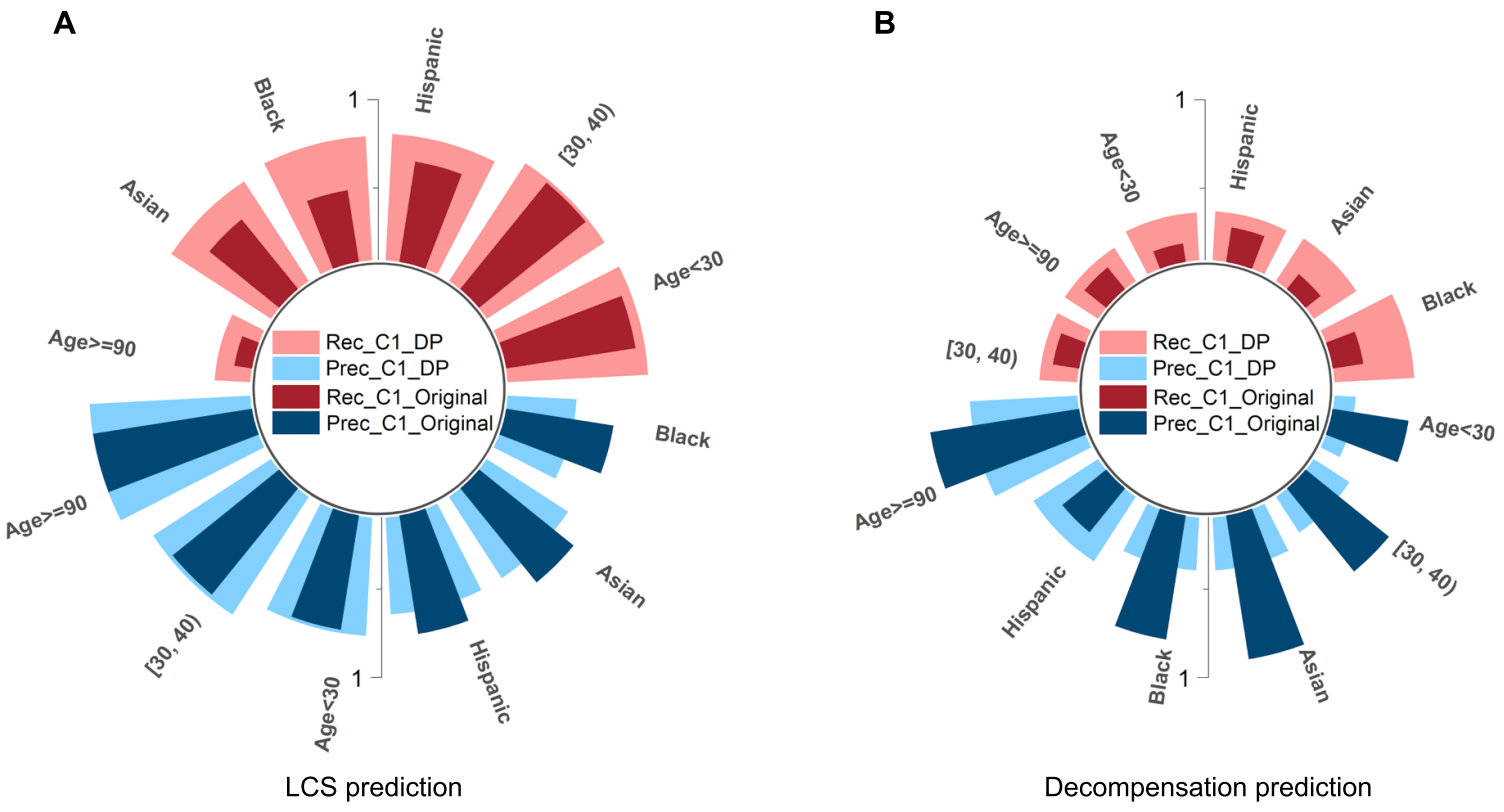